\title{
Estudio filogenético de los géneros de Lithinini de Sudamérica Austral (Lepidoptera, Geometridae): una nueva clasificación
}

\author{
Luis E. Parra ${ }^{1} \&$ Cristián E. Hernández ${ }^{1}$
}

'Departamento de Zoología, Facultad de Ciencias Naturales y Oceanográficas, Universidad de Concepción, Casilla 160-C, Concepción, Chile. luparra@udec.cl

\begin{abstract}
Phylogenetic study of the genera of Lithinini (Lepidoptera, Geometridae) from southern South America: a new classification. In this work we evaluate the taxonomy of the Lithinini of Austral South America based on a phylogenetic analysis. In our analysis we used outgroup Catophoenissa. Two approaches were used to evaluate phylogenetic relationships: 1) parsimony criterion, and 2) Bayesian inference. Parsimony analysis was conducted in PAUP software, and Bayesian analysis with Markov chains Monte Carlo using the BayesPhylogenies software. Our results based on the phylogenetic hypothesis suggest a new taxonomic order for Austral American Lithinini. The valid genera are: Asestra Warren, Acauro Rindge, Calta Rindge, Euclidiodes Warren, Franciscoia Orfila and Schajovskoy, Incalvertia Bartlett-Calvert, Lacaria Orfila and Schajovskoy, Laneco Rindge, Maeandrogonaria Butler, Martindoelloia Orfila and Schajovskoy, Nucara Rindge, Odontothera Butler, Proteopharmacis Warren, Psilaspilates Butler, Rhinoligia Warren and Tanagridia Butler. The main changes with respect to the previous taxonomic order are: 1) Yalpa Rindge is the synonymous junior of Odontothera; 2) the genus Rhinoligia Warren is incorporated into the Lithinini; 3) while our analysis reaffirms that Siopla Rindge is junior synonym of Asestra, Yapoma Rindge and Duraglia Rindge are synonymous of Euclidiodes Warren, while Callemo Rindge and Guara Rindge are synonymous of Tanagridia; 4) the genus Calta Rindge, Incalvertia Rindge, Odontothera Butler and Proteopharmacis Warren, synonymized by Pitkin, are redefined, revalidated and incorporated into the Lithinini tribe. A new species for the genus Franciscoia, F. ediliae Parra is described. A catalogue of the genera and species of the tribe in the region, and the figures of adults and genitalia of some species are included.
\end{abstract}

KEYWORDS. Argentina; Chile; Ennominae; Phylogeny; Taxonomy.

RESUMEN. Estudio filogenético de los géneros de Lithinini de Sudamérica Austral (Lepidoptera, Geometridae): una nueva clasificación. Se evalúa la taxonomía de la tribu Lithinini de Sudamérica Austral sobre la base de un análisis filogenético. Para el análisis se utilizó a Catophoenissa como grupo externo. Se usaron dos aproximaciones filogenéticas para evaluar las relaciones de parentesco: 1) criterio de parsimonia; e 2) inferencia bayesiana. El análisis de parsimonia se realizó a través del programa PAUP y el análisis bayesiano con cadenas de Markov y Monte Carlo a través del programa BayesPhylogenies. Los resultados generados a partir de la hipótesis filogenética permiten proponer una nueva taxonomía para los Lithinini de Sudamérica Austral. Los géneros validos son: Asestra Warren, Acauro Rindge, Calta Rindge, Euclidiodes Warren, Franciscoia Orfila y Schajovskoy, Incalvertia Bartlett-Calvert, Lacaria Orfila y Schajovskoy, Laneco Rindge, Maeandrogonaria Butler, Martindoelloia Orfila y Schajovskoy, Nucara Rindge, Odontothera Butler, Proteopharmacis Warren, Psilaspilates Butler, Rhinoligia Warren, Tanagridia Butler. Los principales cambios respecto de ordenamientos taxonómicos previos son: 1) Yalpa Rindge, es tratado como sinónimo junior de Odontothera. 2) El género Rhinoligia Warren es incorporado a los Lithinini; 3) Se reafirma que Siopla Rindge es sinónimo junior de Asestra, Yapoma Rindge y Duraglia Rindge son sinónimos de Euclidiodes Warren, mientras que Callemo Rindge y Guara Rindge son sinónimos de Tanagridia; 4) Los géneros Calta Rindge, Incalvertia Rindge, Odontothera Butler y Proteopharmacis Warren, sinonimizados por Pitkin, son redefinidos, revalidados e incorporados a la tribu Lithinini. Se describe una nueva especie para el género Franciscoia, F. ediliae Parra. Se incluye un catálogo con los géneros y especies de la tribu de la región, más las figuras de los adultos y genitalias de las principales especies.

PALABRAS CLAVES. Argentina; Chile; Ennominae; Filogenia; Taxonomía.

América del Sur presenta una biota de origen híbrido, porque refleja una historia que la separa claramente en una zona septentrional y meridional (Crisci et al. 1991a y 1991b). En particular la fauna de la región austral de Sudamerica mantiene claras relaciones de parentesco y comparte una historia común con otras áreas como Nueva Zelanda, Tasmania y Australia (Craw 1989, Crisci et al. 1991a, Jerez 1996). Las características actuales de gran parte del cono sur de Sudamerica, y específicamente de Chile y región adyacente, probablemente tienen su origen en el Terciario, cuando el levantamiento de la Cordillera de los Andes produjo un aislamiento de la vertiente occidental de la misma (Moore 1983). Seguramente, los patrones bióticos que se observan en la actualidad, sean producto de los cambios paleoecológicos ocurridos durante el Cuaternario, cuando el avance y retroceso de las glaciaciones produjo la regresión y expansión de los bosques (Simpson 1971, Villagrán \& Varela 1990, Villagrán et al. 1995). Estos fenómenos llevaron cambios en la estructura de las comunidades, por ende, cambios en la composición faunística (Lynch 1990). Muchos taxa se extinguieron y otros usaron la zona como refugio para su mantención en el tiempo, mientras que en otros fomentó la diferenciación y cambios en su distribución (Lynch 1990). Probablemente estos fenómenos hacen de esta zona un área particularmente interesante por la concentración de especies y endemismos en áreas de estrecho rango latitudinal (Crisci 
et al. 1991a; Villagrán \& Hinojosa 1997), y por los rangos discontinuos en la distribución de taxa vegetales (Villagrán \& Hinojosa 1997). En Lepidoptera, muchos grupos muestran altos niveles de endemismo, distribución asociada a los bosques templados de Sudamérica y, afinidades con Nueva Zelanda en los grupos más avanzados y con Australia en los primitivos (Nielsen 1985, Davis 1986, Dugdale 1989), más que con la fauna de la región tropical. Esto último refleja una historia común con áreas australes. Por ejemplo, la familia Geometridae de la región austral de Sudamérica, presenta géneros cuya distribución sugiere que la fragmentación de Gondwana contribuyó a la diferenciación de los mismos y a los patrones de distribución hoy observados (Rindge 1983).

Geometridae es el segundo grupo más diversificado del Orden Lepidoptera (Gaston et al. 1995), con alrededor de 20.000 especies descritas (Munroe 1982, Gaston et al. 1995). Heppner (1991), señala que el 38\% de la fauna de geométridos conocidos en el mundo se concentra en la región Neotropical. La caracterización de esta fauna en particular ha estado a cargo de 8 autores (para una revisión ver Scoble et al. 1995), aunque el mayor esfuerzo se ha concentrado en los trópicos y en menor proporción en el cono sur de América.

Ennominae, una de las seis subfamilias de Geometridae, es la que presenta mayor cantidad de especies descritas (Scoble 1995) y, en ella encontramos varios estudios de géneros que normalmente se incluyen en las diferentes tribus propuestas por Forbes (1948), con la idea de obtener una visión más ordenada de la estructura taxonómica de la subfamilia. El estudio de los geométridos Ennominae del cono sur de América, ha estado directamente relacionado con el esfuerzo de investigación de Rindge (AMNH). En sus trabajos destaca la revisión taxonómica de algunas tribus para la región, como Nacophorini (Rindge 1973 y 1983) y Lithinini (Rindge 1986), ofreciendo una visión más completa de los géneros presentes en Chile y Argentina principalmente.

En la zona de estudio, los primeros datos sobre Lithinini son los de Orfila \& Schajovskoy (1959, 1959, (1960), 1963 y 1964); ellos incluyen distintos géneros sin mencionar expresamente la pertenencia a una tribu en particular, a excepción del género Lacaria para el cual proponen la tribu Lacarini (Orfila \& Schajovskoy 1959). La tribu Lithinini fue redefinida e investigada para el Nuevo Mundo por Rindge (1986), quien incluyó en sinonimia los Lacarini de Orfila y Schajovskoy. Rindge (1986) dividió los géneros del Nuevo Mundo en dos secciones: la primera incluye los géneros de América del Norte y los Holárticos; la segunda, está constituida por 19 géneros sudamericanos. En esta sección hace una revisión detallada de los géneros que la componen e incluyendo los aportes de Orfila y Schajovskoy (1959). Pitkin (2002) en su revisión de los Ennominae neotropicales, reduce a 12 los géneros sudamericanos de la tribu introduciendo varios cambios taxonómicos. Estos cambios involucran exclusión de géneros, nuevas sinonimias de géneros y especies y nuevas combinaciones. Sin embargo, a pesar de estas recientes revisiones, no existe a la fecha un análisis filogenético basado en caracteres morfológicos de las especies tipos de los diferentes géneros, lo cual muestra que la situación taxonómica de los géneros del sur de Sudamérica aún podría manifiestar muchos problemas por resolver. Entonces, a partir de un análisis filogenético de los taxa de la región austral de Sudamérica, el presente estudio entrega un nuevo ordenamiento taxonómico de los géneros y especies presentes en la tribu, que incluye la incorporación y revalidación de géneros, y nuevas sinonimias y combinaciones para los nombres previos a este estudio.

\section{MATERIAL Y MÉTODOS}

Se revisaron más de 1000 ejemplares de las colectas realizadas en varios años de trabajo de campo, incluyendo la mayoría de los ejemplares tipos de las especies citadas para Chile y material depositado en el Museo Nacional de Historia Natural, Santiago, Chile (MNHN), Museo de Zoología de la Universidad de Concepción, Concepción, Chile (MZUC), Instituto Miguel Lillo, San Miguel de Tucumán, Argentina (IML), Museo Argentino de Ciencias Naturales; Buenos Aires, Argentina (MACN) y The Natural History Museum, London, UK (BMNH). Los ejemplares examinados se incluyen en el Anexo 1.

Las asignaciones taxonómicas de este estudio están basadas en el examen detallado de ejemplares de las diferentes especies de cada uno de los géneros tratados más adelante. Además, los géneros Euclidiodes y Psilaspilates poseen recientes revisiones (Parra 1999a y Parra 1999b). Las especies de cada género están señaladas en la lista sistemática que se incluye en los resultados del trabajo, en ella se indica la sinonimia definitiva de cada una de ellas. En las observaciones de cada uno de los géneros se entrega un breve comentario de las sinonimias. Las especies más sus sinonimias entregan el número de especies de cada género. Al no contar con ejemplares para un análisis más detallado la información para los géneros Acauro, Laneco y Asestra se obtuvo directamente de las descripciones del trabajo de Rindge (1986) y Pitkin (2002). Se entrega una descripción detallada solamente de aquellos géneros que han sufrido modificaciones, los que son revalidados e incorporados en este estudio a la tribu.

Basados en la morfología del grupo Lithini nosotros utilizamos dos enfoques filogenéticos distintos para evaluar las relaciones entre sus taxa componentes: (1) el criterio de optimización de máxima parsimonia (MP), y (2) métodos basados en inferencia bayesiana. En ambos análisis filogenéticos usamos los caracteres de Catophoenissa como grupo externo, dado que este taxón tiene una relación filogenética cercana conLithini(Pitkin 2002). La aproximación de MP se realizo en el programa PAUP* (Swoford 2002), en el cual los datos fueron tratados como no ordenados y de igual peso. Para encontrar el árbol filogenético de MP usamos una búsqueda branch and bound (enumeración implícita) en el espacio de árboles. Adicionalmente, la consistencia de nodos del árbol de MP fue estimada por la técnica de bootstrapping no-paramétrica (Felsenstein 1985) con 1.000 pseudoreplicas, y a través del índice de decaimiento o "Bremer support" (Bremer 1994) calculado con el programa PRAP2 (Müller 2004, 2005; Wall et al. 2008).

Nosotros usamos el método de Cadenas de Markov y Monte Carlo (MCMC) dentro de un marco Bayesiano (de ahora en adelante BMCMC) para estimar la probabilidad a posteriori 


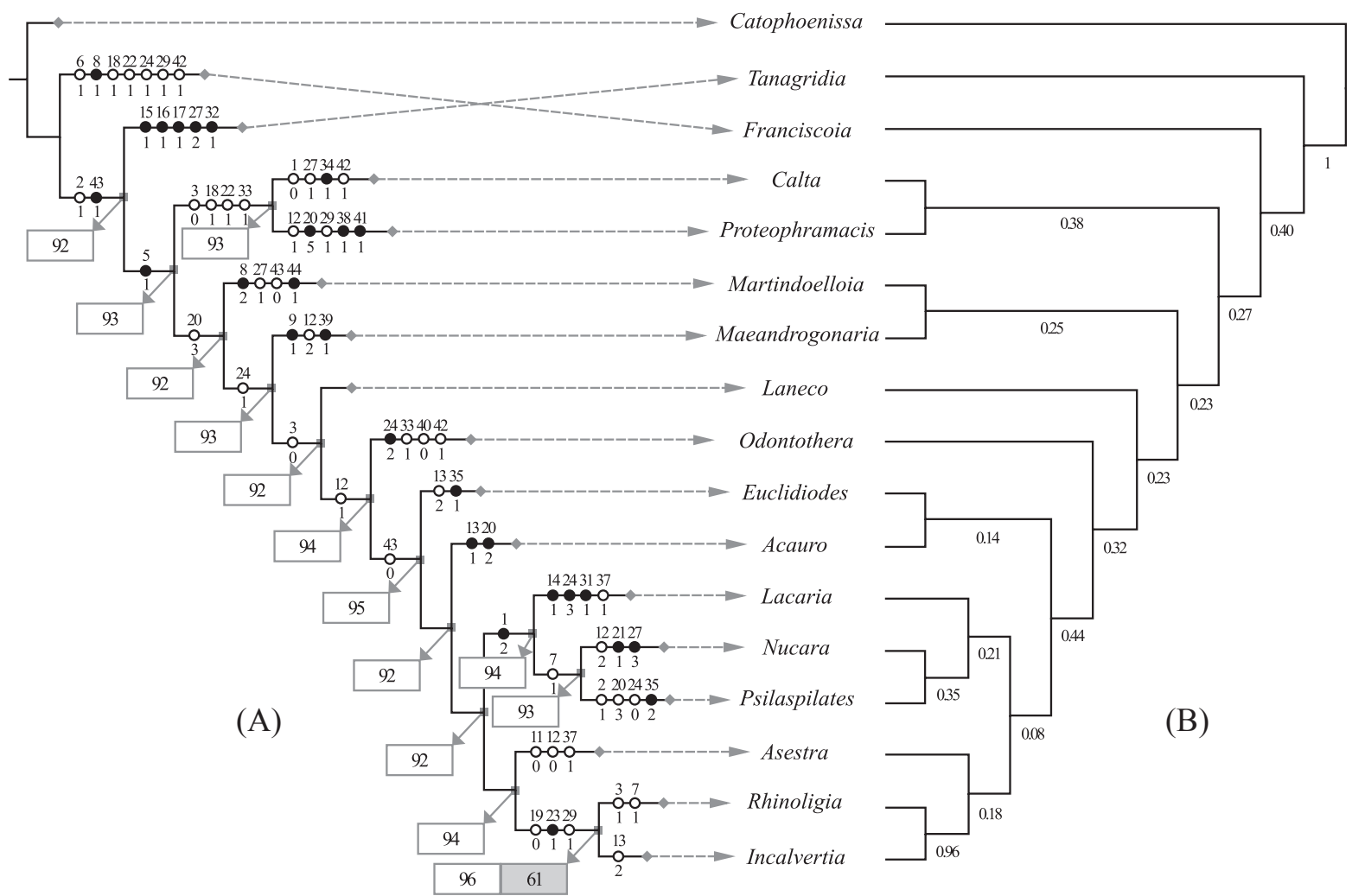

Fig. 1. (A) Criterio de optimización de Máxima Parsimonia: árbol de consenso de la regla de la mayoría de más de 215 árboles parsimoniosos de igual longitud (longitud del árbol $=96$, índice de consistencia $=0.59$, índice de retención $=0,53$ ). Los números de los caracteres en las ramas del árbol se estableció utilizando WinClada (Nixon, 2002). Los círculos negros indican apomorfías (sinapomorfías o autapomorfías), los círculos blancos muestran homoplasias. La etiqueta gris muestra el porcentaje de apoyo superior a 50\% en Bootstrapping y las etiquetas blancas los valores del índice de decaimiento o "Bremer support". (B) Inferencia bayesiana: árbol de consenso de la regla de mayoría de 80.383 árboles construidos a partir del modelo M2P. Los números en los nodos son las probabilidades posteriores. Este es el número de veces que un determinado nodo apareció en la muestra MCMC y que es interpretado como la probabilidad posterior de que el nodo es verdadero.

de los árboles filogenéticos. El procedimiento de MCMC asegura que los árboles sean muestreados en proporción a sus probabilidades de ocurrencia bajo el modelo de evolución morfológica usado. El análisis filogenético bayesiano fue implementado en el programa BayesPhylogenies, disponible por petición al Dr. Mark Pagel (m.pagel@rdg.ac.uk) o en el sitio web http://www.evolution.rdg.ac.uk/BayesPhy.html (Pagel \& Meade 2004). Para la estimación a posteriori de los parámetros de los árboles a través de las cadenas en este análisis se partió las Cadenas de Markov con un árbol aleatorio y probabilidad a priori uniforme.

Aproximadamente 80.433 .000 árboles filogenéticos fueron generados utilizando el procedimiento de BMCMC, submuestreando cada 1.000 árboles para asegurar que las muestras sucesivas fueron independientes. Para asegurar que las cadenas de Markov alcanzaron un equilibrio estable (i.e. zona de convergencia de las cadenas de markov), los valores de verosimilitud de los puntos de muestreo fueron graficados en función de las generaciones corridas en la cadena. Todos los árboles antes del punto en cuál valores verosimilitud alcanzaron la distribución estacionaria fueron descartados (i.e. quemados $=50$ árboles); luego nosotros sólo utilizamos la muestra restante para estimar la distribución a posteriori de probabilidad de los árboles filogenéticos. Para asegurar que el análisis no quedara atrapado en un óptimo local, cinco cadenas independientes fueron realizadas. Se considero que los análisis independientes convergieron si los valores de verosimilitud media de la zona de convergencia fueron similares (Huelsenbeck \& Bollback 2001).

El modelo de evolución morfológica que utilizamos en la aproximación BMCMC fue el modelo morfológico de tiempo no-reversible (de ahora en adelante M2P) que utiliza los caracteres codificados como 0 o 1 , este modelo permite que la tasa de cambio evolutiva de 0 a 1 difiera de la tasa de cambio de 1 a 0 . Por último, para obtener la hipótesis filogenética basada en probabilidades nosotros importamos la muestra de árboles de la zona de convergencia de nuestro análisis de BMCMC en el programa PAUP* (Swofford 2002), y estimamos un consenso de la regla de la mayoria de los 80,383 árboles construidos con el modelo M2P, en este árbol la frecuencia de los nodos es equivalente a la probabilidad de que el nodo sea el verdadero nodo.

La lista de caracteres y códigos usados se muestran en las tablas I y II para 17 taxa y 44 caracteres. Los taxa considerados han sido los 17 géneros de la tribu Lithinini que habitan en la región objeto de estudio y que son endémicos de esta zona. El objetivo de este análisis es establecer las relaciones filogenéticas entre ellos, y si su endemismo responde además a una monofilia. 

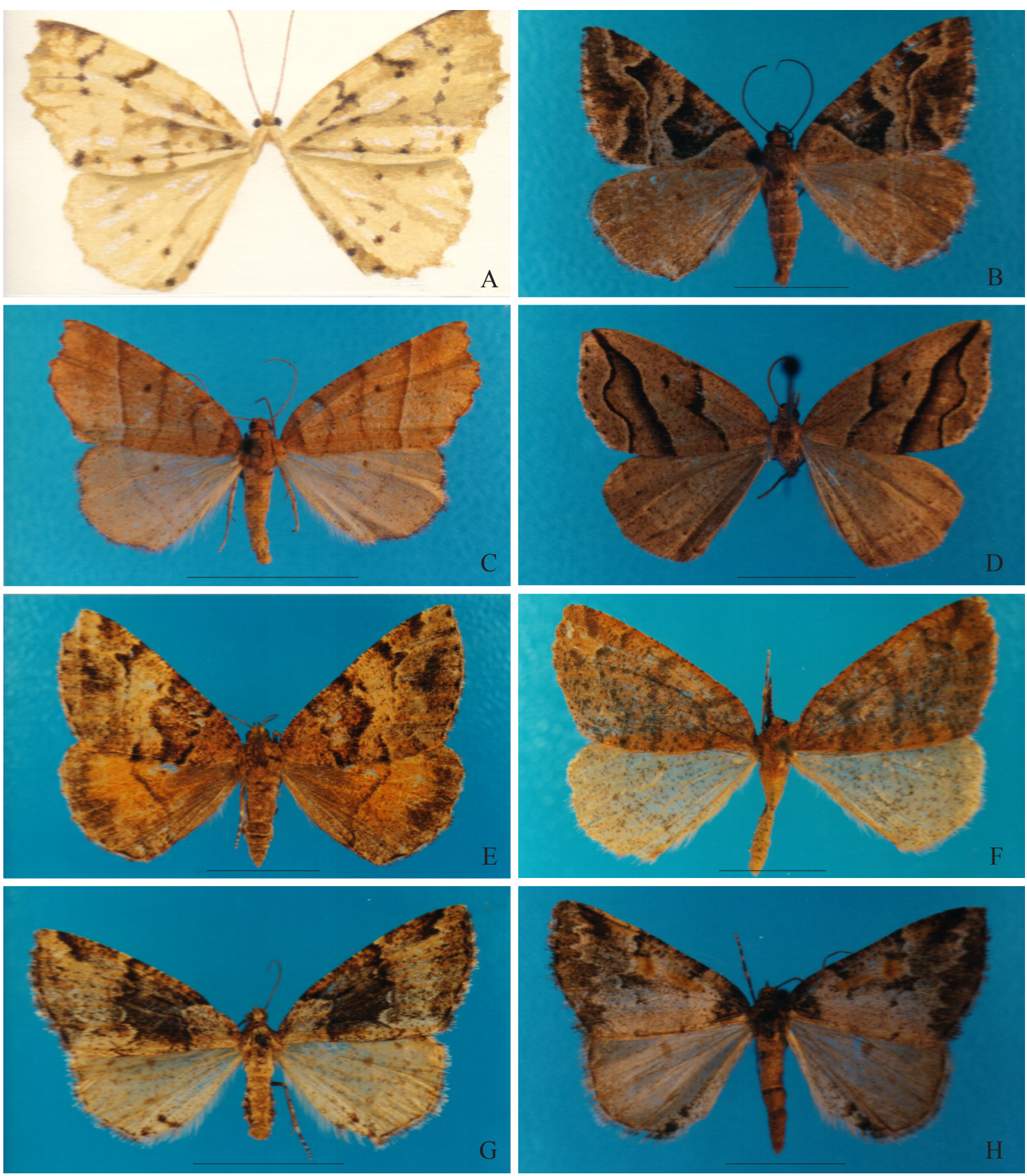

Fig. 2. Especies de Lithinini de Sudamérica austral. a) Calta. debilis; b) Euclidiodes agitata; c) Franciscoia morenoi; d) Tanagridia raphis; e) Incalvertia valdiviana; f) Franciscoia ediliae; g) Lacaria araucanaria; y f) Lacaria orfilai. Escala $1 \mathrm{~cm}$.

\section{RESULTADOS}

\section{Diagnosis de los Lithinini}

Los caracteres diagnósticos diferenciales de las tribus de la subfamilia Ennominae, se refieren a caracteres de la genitalia del macho. Los Lithinini pueden distinguirse de otros Ennominae en la estructura del anellus y de su proceso. Proceso del anellus generalmente largo y delgado, en muchos casos lleva cerdas o espinas en su superficie o en el ápice. El proceso del anellus se localiza en el margen posterior o latero-posterior de la yuxta. El anellus es reducido en tamaño y se localiza dorsalmente en relación a la superficie interna de las valvas. Rindge (1986) indica la presencia de cristae en las valvas del macho para todos los géneros de Lithinini exceptuando Catophoenissa y Tacparia; aquí se considera esencial este carácter y representa para los géneros sudamericanos una sinapomorfía, por ello Catophoenissa es excluida de la tribu.

Los Nacophorini (Rindge 1983), muestran muchas características comunes con los Lithinini, pero en este caso el proceso del anellus es corto, de base ancha, generalmente curvo y termina en una punta. El anellus tiende a ser grande, 

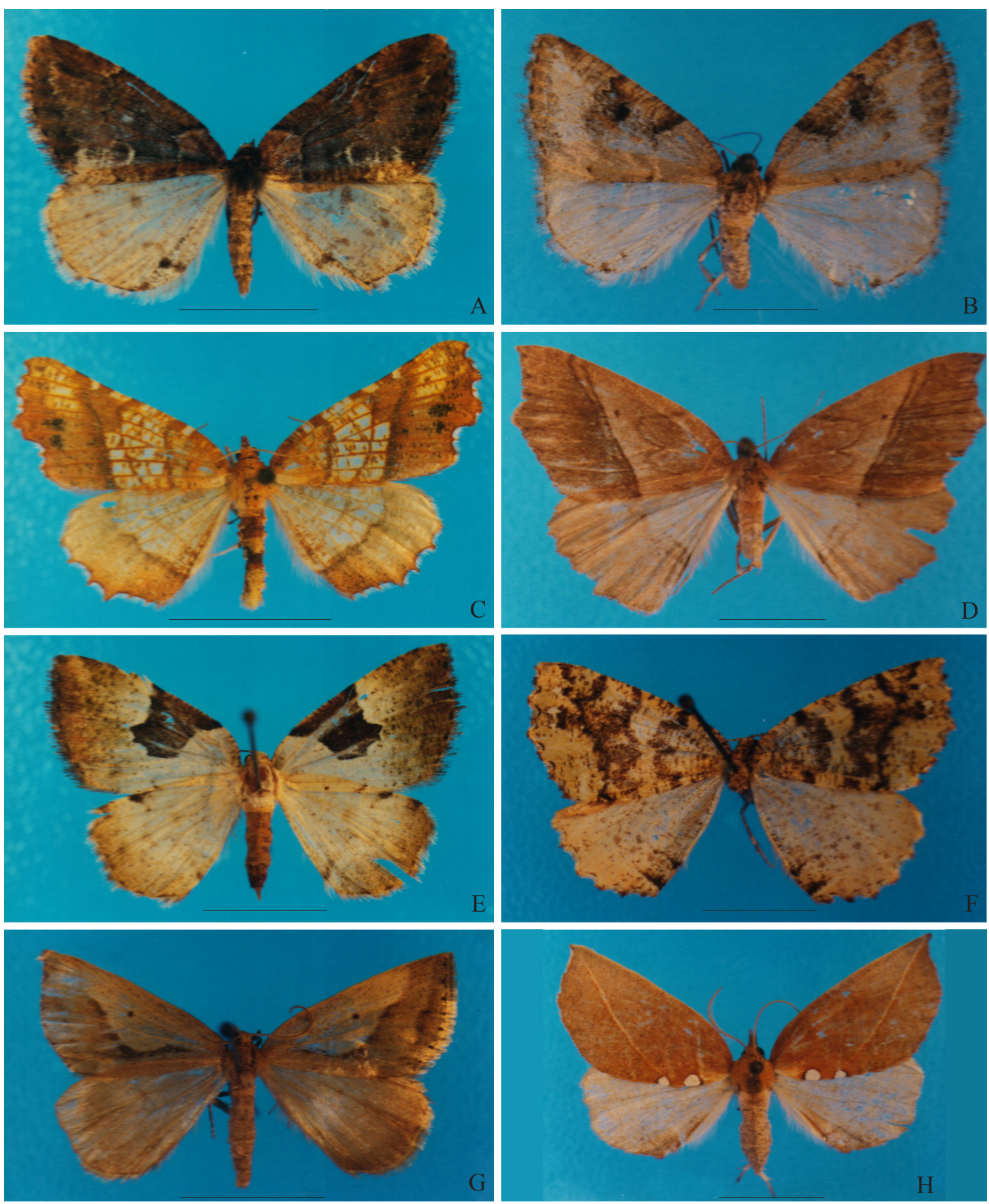

Fig. 3. Especies de Lithinini de Sudamérica austral. a) Lacaria picuncharia; b) Lacaria schajovskoyi; c) Maeandrogonaria valentina; d) Martindoelloia juradoi; e) Nucara recurva; f) Odontothera debilis; g) Psilapilates catillata; y f) Rhinoligia biocellata. Escala $1 \mathrm{~cm}$.

generalmente lleva una extensión posteromedial y está situado ventralmente a la superficie interna de las valvas.

Filogenia de los géneros de Lithinini de América Austral Consideraciones preliminares

La filogenia de la subfamilia Ennominae ha sido estudiada por Rindge (1964, 1966, 1967, 1971, 1973, 1975, 1978, 1983 y 1986) y McGuffin (1972, 1977, 1982 y 1987), a partir del análisis de la fauna de las regiones Neártica y Neotropical. En sus trabajos, Rindge da una lista de caracteres polarizados, considerando que los Boarmini presentan una condición ancestral. Rindge (1986) concluye que no es posible establecer la monofilia de los Lithinini usando solamente caracteres del imago y que sólo un análisis comparado de los estados preimaginales permitirá establecer conclusiones 

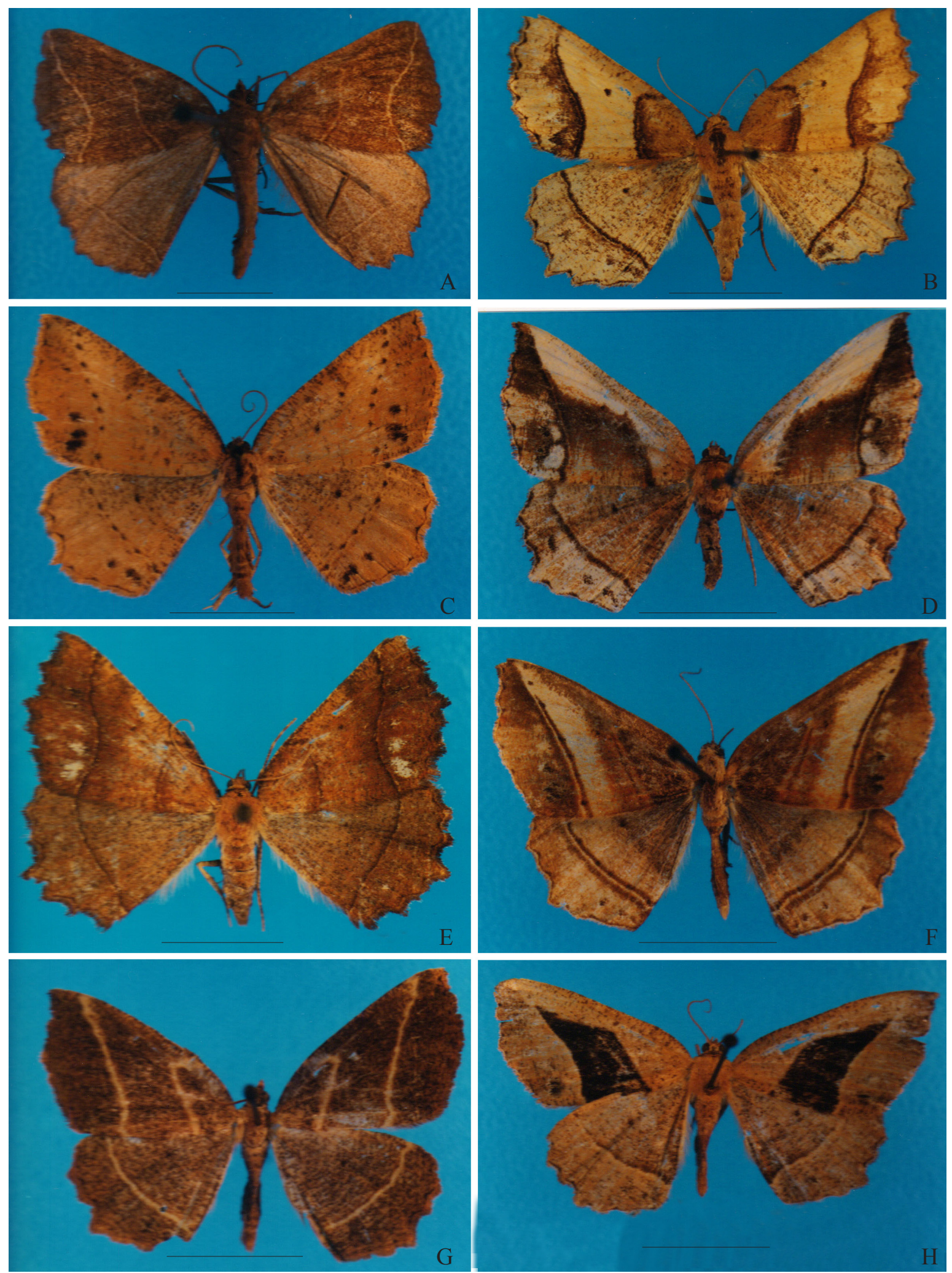

Fig. 4. Especies de Lithinini de Sudamérica austral. a-h) Protepharmacis valdiviata. Escala $1 \mathrm{~cm}$.

más definitivas sobre los parentescos existentes entre sus entidades taxonómicas.

McGuffin (1987) entrega un resumen general y muy detallado de los probables pasos en los orígenes de las diferentes tribus de esta subfamilia, basándose en caracteres del imago (fundamentalmente siguiendo a Rindge) y de los estados inmaduros. Supone que el ancestro de los Ennominae es del tipo Boarmini (McGuffin 1977), el cual presumiblemente tenía las antenas pectinadas en el macho, espolones sólo en la tibia metatorácica y las alas anteriores 


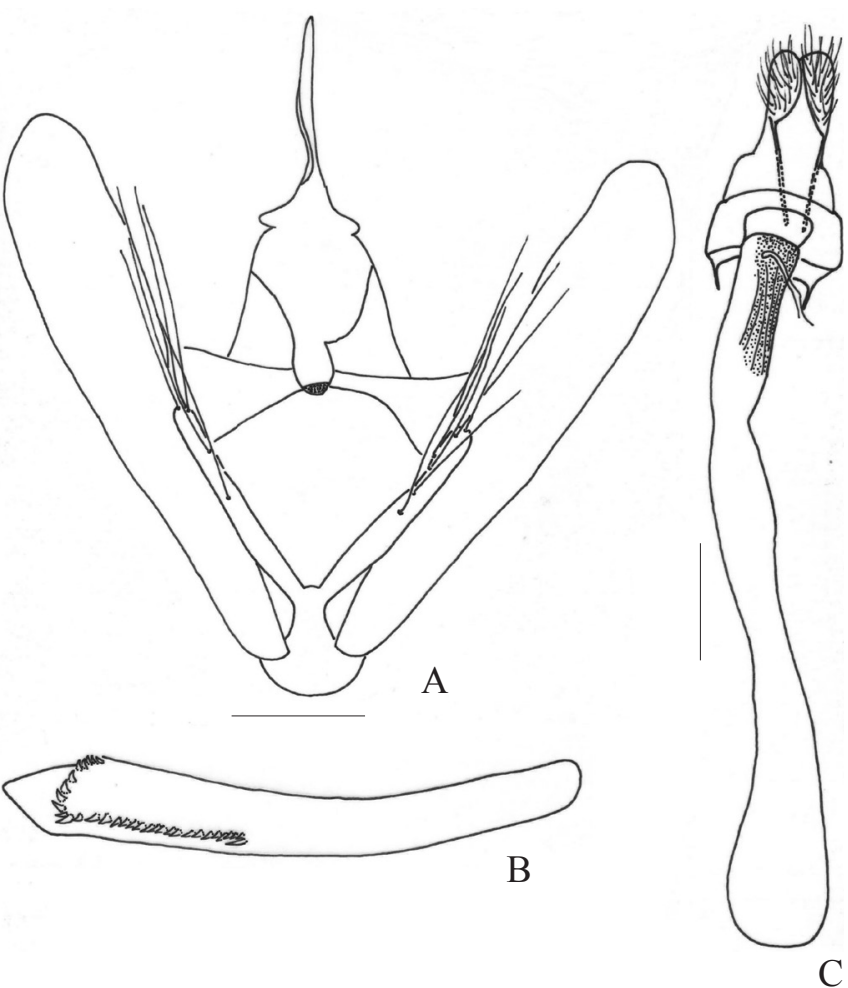

Fig. 5. Armaduras genitales del macho y hembra de Calta debilis. a) genitalia del macho en vista ventral; b) aedeagus en vista lateral; y c) genitalia de la hembra en vista dorsal. Escalas $0,25 \mathrm{~mm}$, figura c $1 \mathrm{~mm}$.

con 12 venas y sin fóvea. La genitalia del macho del tipo simple y la vesica con varios cornuti o espinas. La genitalia de la hembra con apófisis posteriores largos, esterigma membranoso y en la bursa copulatrix con la presencia de un signum. De acuerdo a su análisis, en el ancestro de los Lithinini se encontraban los siguientes estados de caracteres: macho con antena pectinada, dos pares de espolones en la tibia metatorácica, y la genitalia con un uncus delgado, valva redondeada apicalmente y la presencia de cornuti en la vesica. En la genitalia de la hembra, las apófisis posteriores cortas, el ductus bursae moderado en longitud y el corpus bursae con un signum. La larva monocroma con líneas oscuras, con la cerda $V_{1}$ sobre $A_{1}$ y anteroventral a la cerda $S_{1}$. Pupa con fémur protorácico y con 8 cerdas en el cremáster. Holloway (1993 (1994)) indica que las larvas se caracterizan por poseer seis cerdas dispuestas en la cara externa de los espuripedios.

\section{Análisis filogenético}

En el análisis de parsimonia se obtuvieron 215 árboles igualmente parsimoniosos $(\mathrm{L}=96, \mathrm{Ci}=0,59, \mathrm{Ri}=0,52)$. Los altos niveles de homoplasia $(\mathrm{RCi}=0,307)$ generaron árboles con politomías. El árbol de consenso de este análisis, obtenido por la regla de la mayoría, se muestra en la figura 1A. Este árbol muestra un alto valor de bootstrapping en el nodo Rhinoligia + Incalvertia $($ Valor $=61)$, y en general altos valores del índice de decaimiento o "Bremer support" lo cual da un alto sustento al árbol obtenido. El análisis de inferencia Bayesiana para estimar la probabilidad a posteriori de los

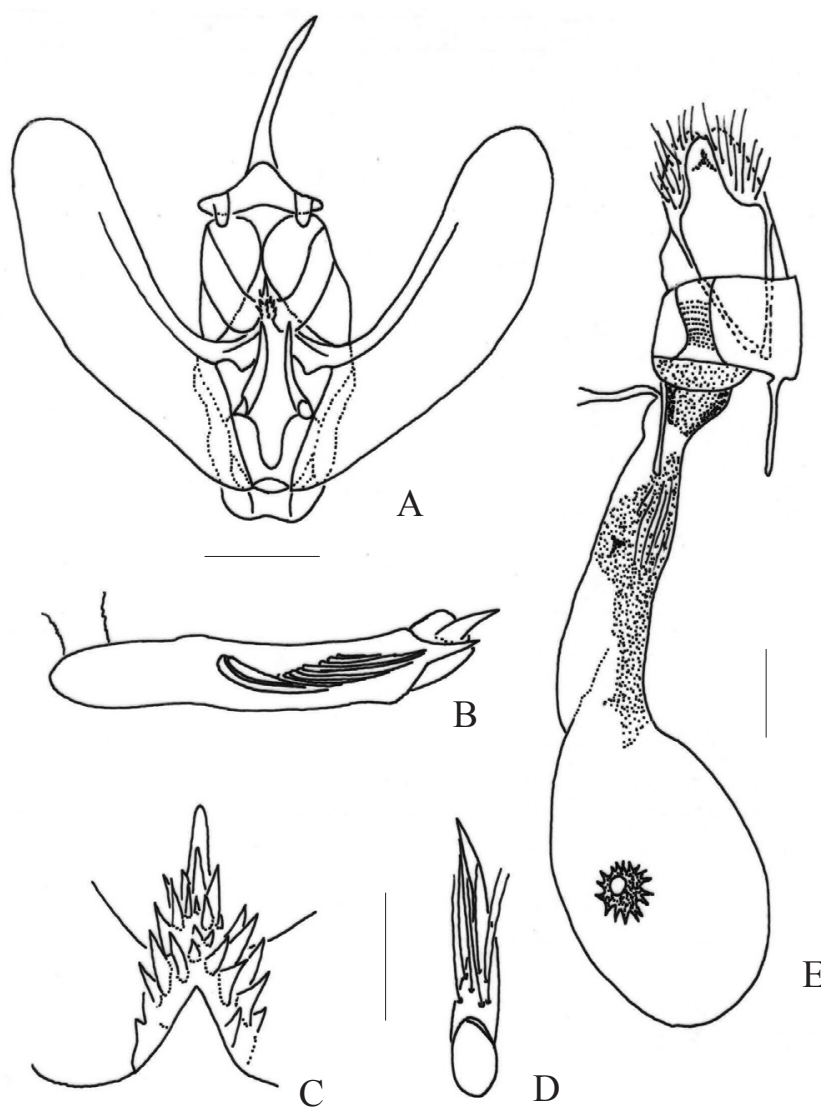

Fig. 6. Armaduras genitales del macho y hembra de Euclidiodes agitata. a) genitalia del macho en vista ventral; b) aedeagus en vista lateral; c) extremo del gnathos; d) proceso del anellus; y e) genitalia de la hembra en vista ventral. Escalas $0,25 \mathrm{~mm}$, figura e $0.5 \mathrm{~mm}$.

árboles filogenéticos, se muestra en la figura 1B. Según estos análisis, todos los géneros forman un grupo monofilético sustentado por las siguientes sinapomorfías: (1) ausencia de penachos metatorácicos; (2) ausencia de penachos abdominales; (3) cristae presente; y (4) funda del aedeagus sin una proyección triangular o rectangular en el ápice posterior. Además, los siguientes caracteres, que comparten las especies del sur de Sudamérica, serían las probables sinapomorfías de todos los Lithinini (Pitkin 2002): el anellus es reducido en tamaño y se localiza dorsalmente en relación a la superficie interna de las valvas; el proceso del anellus es generalmente largo y delgado, en muchos casos lleva cerdas o espinas en su superficie o en su ápice y se localiza en el margen posterior o latero-posterior de la yuxta. Los clados sustentados por sinapomorfias son(Fig. 1A): Lacaria +Nucara + Psilaspilates, apoyado por la antena serrada en los machos; y Rhinoligia + Incalvertia, por el origen lateroanterior del proceso del anellus con respecto al anellus. El análisis bayesiano muestra clados sustentados con baja probabilidad a posteriori, en los que destacan: Calta + Proteopharmacis, sustentada por 0,38; Martindoelloia + Maeandrogonaria con un 0,25; Lacaria + Nucara + Psilaspilates con un 0,21; y Asestra + Rhinologia + Incalvertia con un 0,18. En este último análisis, Rhinologia + Incalvertia muestran una alta probabilidad de relación filogenética cercana $(0,98)$. La monofilia de los otros clados 


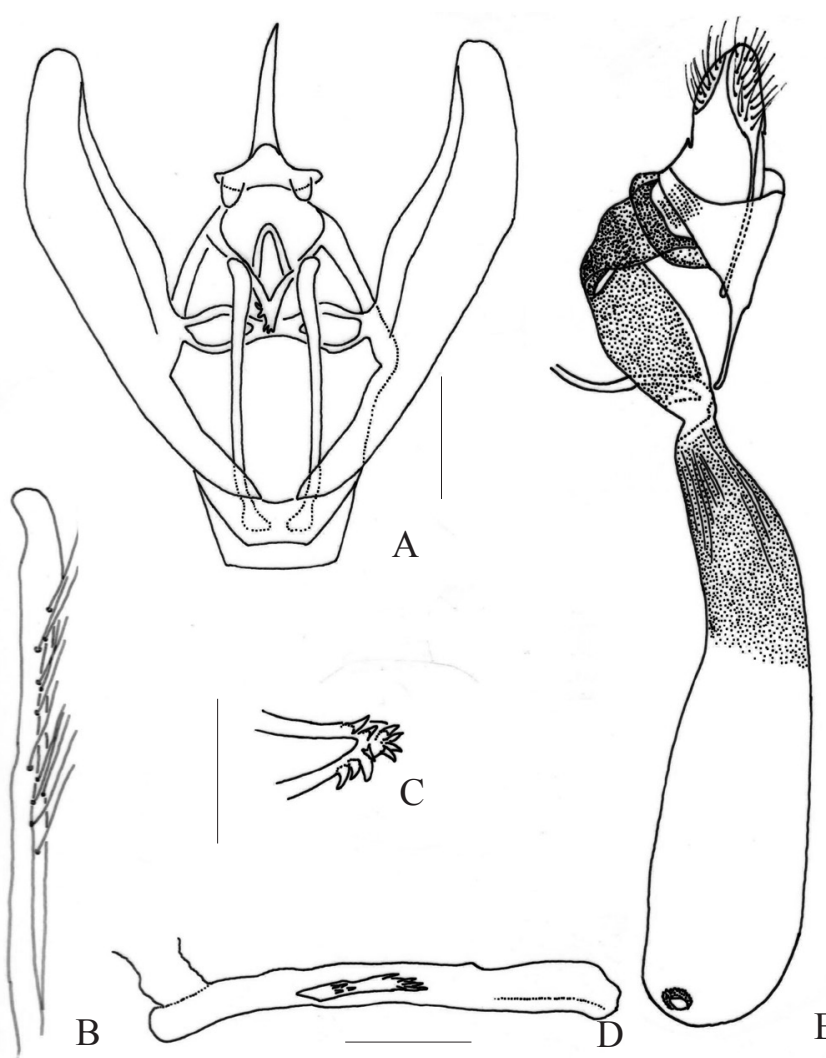

Fig. 7. Armaduras genitales del macho y hembra de Franciscoia morenoi. a) genitalia del macho en vista ventral; b) proceso del anellus; c) extremo del gnathos; d) aedeagus en vista lateral; y e) genitalia de la hembra en vista ventral. Escalas $0,25 \mathrm{~mm}$, figura e $0,5 \mathrm{~mm}$.

no está sustentada por carácter alguno, su parentesco es establecido por una serie de caracteres simplesiomórficos. La mayoría de los géneros presentan autapomorfias que lo definen, excepto los géneros Laneco, Asestra, Rhinoligia e Incalvertia.

Taxonomía. Descripción de los géneros

\section{Calta Rindge, 1986}

Calta Rindge 1986:49.

Especie tipo: Calta lamella Rindge 1986:51. Por designación original.

Descripción. La apariencia general de la polilla se muestra en la figura 2a. Polillas de tamaño medio a grandes, la longitud del ala anterior varía entre 16 y $20 \mathrm{~mm}$.

Antena lamelada en el macho, simple en la hembra; palpo labial concoloro con las alas; su artículo medio $1 / 3$ más largo que el distal. Las alas anteriores grises, con las bandas ante, medial y postmedial marcadas. Alas posteriores blanco grisáceas. Venación alas anteriores: sin celda accesoria. Venación alas posteriores: $\mathrm{Sc}$ y Rs paralelas; vena $\mathrm{M}_{2}$ representada por un pliegue, no tubular. Patas: oscuras en su lado externo, claras en el interno; tibia metatorácica del macho con un pincel de pelos; fórmula tibial 0-2-4. Abdomen concoloro con las alas; machos sin fila de cerdas en el lado ventral del tercer segmento abdominal.
Genitalia del macho (Figs. 5a-b). Anellus reducido; proceso del anellus largo y delgado, extremo apical cubierto con numerosas cerdas mucho más largas que el mismo.

Genitalia de la hembra (Figs. 5c). Corpus bursae membranoso, muy largo, delgado, sin signum.

Diagnosis y monofilia. Este género monotípico se distingue de todos los otros de la tribu por ser el único en que el macho tiene antenas lameladas. Las alas anteriores son grises, las bandas castaño oscuras, con tres triángulos blancos en el margen externo cerca del ápice. Estas características de la maculación, lo asemejan bastante a los géneros Acauro y Odontothera, pero difiere de ellos en la morfología de la armadura genital del macho como de la hembra. Genitalia del macho, proceso del anellus largo y delgado terminado en cerdas apicales, tan largas como la longitud del mismo; vesica con una hilera de espinas (cornuti) distribuidas en un ángulo de $90^{\circ}$. Genitalia de la hembra, corpus bursae largo y delgado, membranoso, signum ausente.

Distribución. Probablemente Valdivia sea la localidad tipo, y aunque no está citada en el ejemplar tipo de Odontothera debilis Butler (= Calta lamella), sí aparece en la descripción de Butler (1882). La única especie ha sido capturada en otras 4 localidades. La especie es endémica, su registro más septentrional es Valdivia (39 30` S) y el más austral Llanquihue ( $\left.43^{\circ} 30^{\prime} \mathrm{S}\right)$. Su distribución está asociada al bosque valdiviano y nordpatagónico y bosque templado frío de Nothofagus. Probablemente la especie tenga un registro más septentrional del que se menciona aquí.

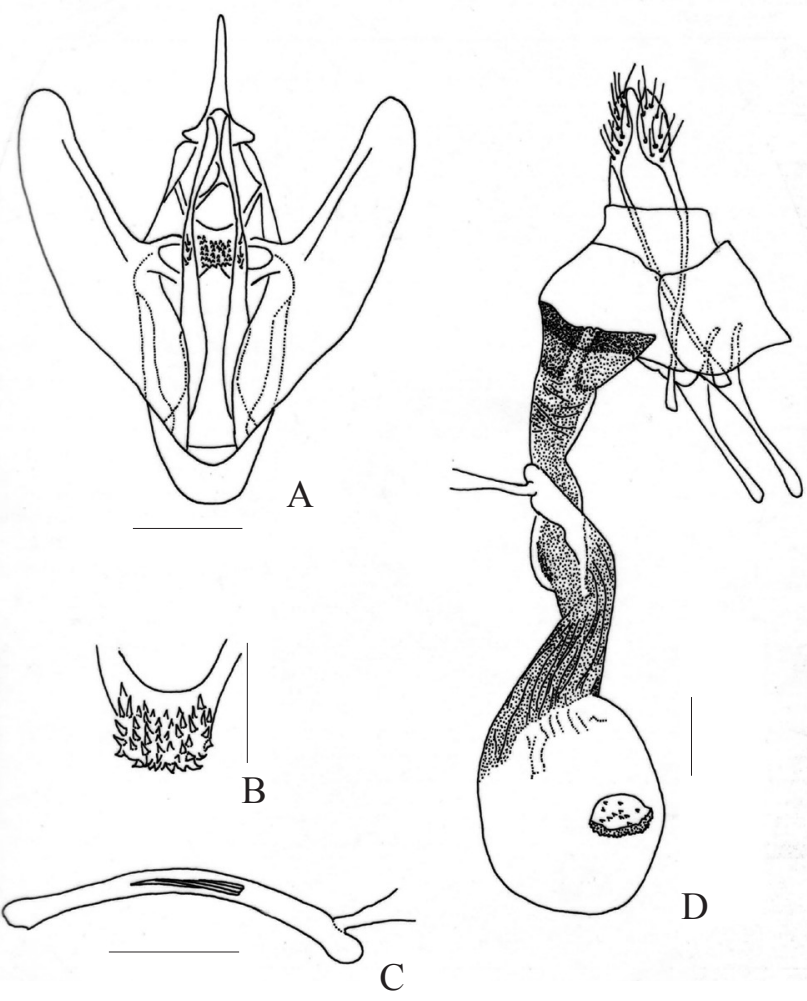

Fig. 8. Armaduras genitales del macho y hembra de Franciscoia ediliae. a) genitalia del macho en vista ventral; b) extremo del gnathos; c) aedeagus en vista lateral; y d) genitalia de la hembra en vista dorsal. Escalas $0,25 \mathrm{~mm}$, figura e $0.5 \mathrm{~mm}$. 


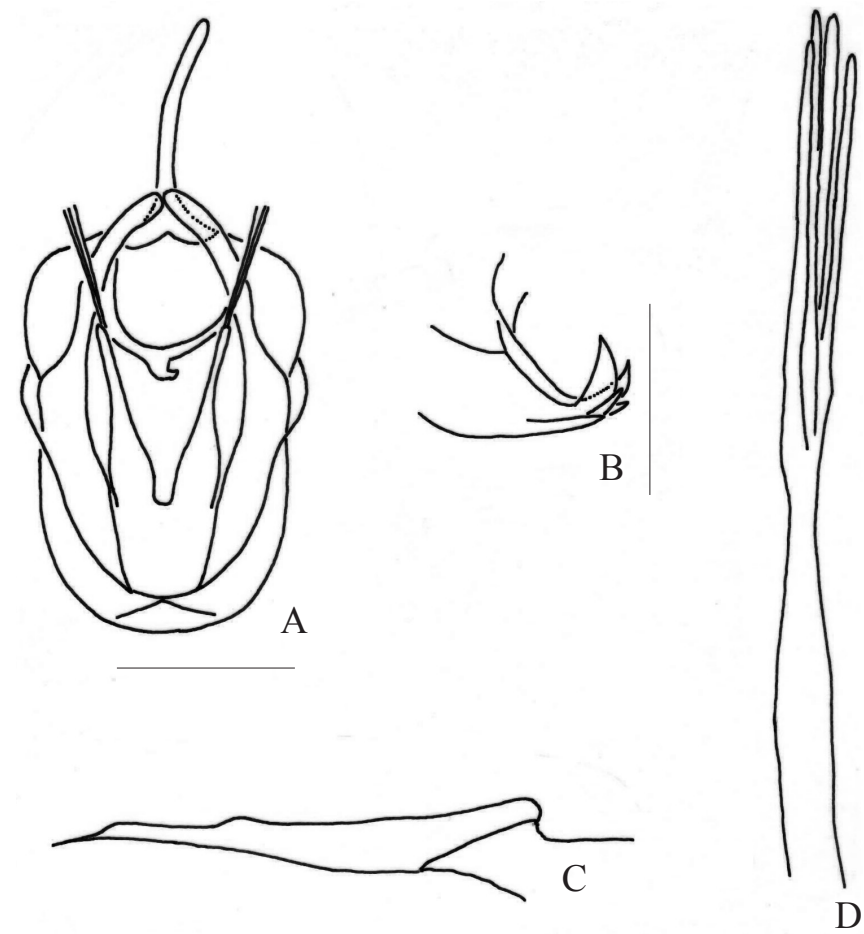

Fig. 9. Armadura genital del macho de Tanagridia raphis. a) genitalia del macho en vista ventral; b) extremo del gnathos; c) aedeagus en vista lateral; y d) proceso del anellus. Escalas $0,25 \mathrm{~mm}$.

Observaciones. Rindge (1986) describió el género para su nueva especie Calta lamella. Pitkin (2002) incluye al género Calta Rindge en la sinonimía del género Odontothera Butler por la presencia de un ángulo en el extremo final de la hilera de espinas de la vesica. La posesión de un proceso del anellus largo y terminado en cerdas distintos al observado en Odontothera (sensu este estudio) más las antenas lameladas del macho, permite revalidar el género descrito por Rindge (1986). Tal y como concluye Pitkin (2002), la revisión de los ejemplares tipos de las especies Calta lamella Rindge como de Odontothera debilis Butler, permite establecer que esta última especie es el sinónimo senior de C. lamella Rindge. Se considera válido el género descrito por Rindge, pues los caracteres de Calta debilis son totalmente diferentes a los de Odontothera y al resto de los géneros incluidos en esta tribu.

Rindge (1986) indica que la vesica de C. debilis es inerme, lo que se contradice con su ilustración del aedeagus (p. 35) y con los datos aportados aquí. Sólo el material tipo y dos ejemplares más han sido examinados, todos depositados en el BMNH.

\section{Euclidiodes Warren, 1895}

Euclidiodes Warren 1895:141.

Euclidiodes Warren. Orfila \& Schajovskoy 1959 (1960):8; Fletcher 1979:80; Rindge 1986:55.

Aspilaria Staudinger 1898 (1899):93 (Sinonimia establecida por Pitkin, 2002:192).

Aspilaria Staudinger. Fletcher 1979:21.

Catriela Orfila \& Schajovskoy 1959 (1960): 12.

Catriela Orfila \& Schajovskoy. Fletcher 1979:38.
Duraglia Rindge 1986:59 (Sinonimia establecida por Pitkin, 2002:192).

Yapoma Rindge, 1986:57 (Sinonimia establecida por Pitkin, 2002:192).

Especies tipos: Heterophleps ophiusina Butler 1882:423, para Euclidiodes designada por Warren 1895:141.

Aspilates citrinarius Mabille 1885:67, para Aspilaria, designada por Fletcher 1979. In: Nye:21.

Heterophleps agitata Butler 1882:423, para Catriela, designada por Orfila \& Schajovskoy 1959 (1960): 12.

Duraglia xhante Rindge 1986:60. Por designación original.

Yapoma chone Rindge 1986:58. Por designación original.

El género, el cual incluye siete especies, fue revisado por Parra (1999b), por ello la información presentada aquí es restringida.

Diagnosis y monofilia. Las especies incluidas en este género no parecen estar relacionadas cuando se comparan y analizan la coloración y patrones de maculación. Sin embargo, un estudio de la genitalia más otros caracteres, indican que estas especies son congenéricas.

Euclidiodes en la genitalia del macho comparte la forma de "W" del gnathos (Fig. 6a y c) con los géneros Acauro e Incalvertia, se distingue fácilmente de ellos por el proceso del anellus, el cual es membranoso, curvo y cubierto de cerdas dispersas (Fig. 6d). La presencia de un grupo de espinas de similar tamaño se constituye en la autapomorfía para el género. En la hembra la presencia de un corpus bursae esférico o subesférico y membranoso, más la presencia de un signum estrellado o subestrellado, permitiría distinguir a las especies de otras (Fig. 6e).

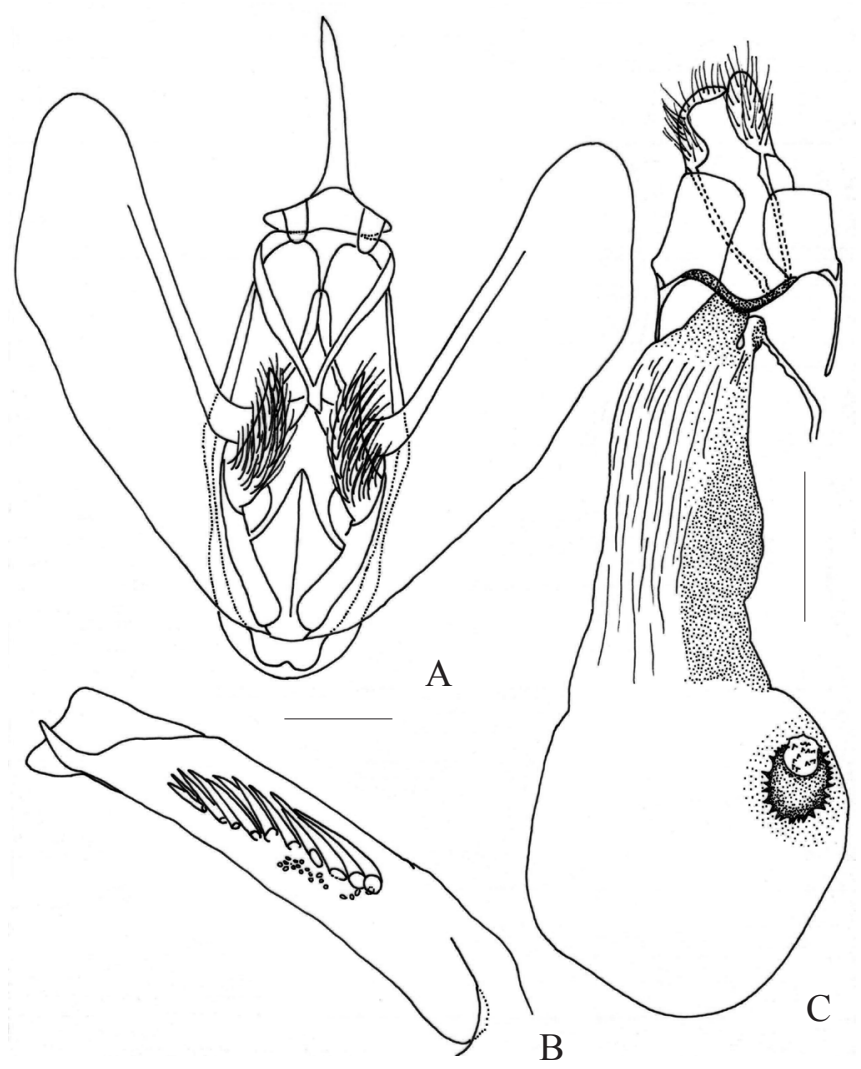

Fig. 10. Armadura genital del macho de Rhinoligia biocellata. a) genitalia del macho en vista ventral; b) aedeagus en vista lateral; y c) genitalia de la hembra en vista latero ventral. Escala $0,25 \mathrm{~mm}$, figura c $1 \mathrm{~mm}$. 
Tabla I. Caracteres polarizados para el análisis filogenético de los géneros de la tribu Lithinini en el presente estudio

1. Antena del macho simple (1) o serrada (2); pectinada o laminada (0)

2. Palpo labial tan o más largo que el diámetro del ojo (1); igual o más corto (0)

3. Superficie ventral de la frente con un penacho de escamas (1); ausente (0)

4. Penacho metatorácico ausente (1); presente (0)

5. Tibia metatorácica del macho con un pincel de pelos (1); sin pincel de pelos (0)

6. Con una celda accesoria en las alas anteriores (1); sin celda accesoria (0)

7. Alas anteriores con bandas ( 0 ) y sin bandas transversales (1)

8. Alas anteriores con tres bandas transversales (0), con cuatro (1) con dos (2)

9. Alas anteriores del macho sin fóvea (0) con fóvea (1)

10. Penachos en la región dorsal del abdomen ausentes (1); presentes (0)

11. Cerdas ventrales en el tercer esternite abdominal del macho (1); ausente (0)

12. Socius en forma de cojín, reducido (0), digitiforme (1), elongado (2)

13. Gnathos en forma de "W" (2); en forma de "U" (1) o "V" (0)

14. Proceso costal de las valvas presente (1); ausente (0)

15. Valvas con valvula (1); ausente (0)

16. Valvas ampliamente unidas al saccus-vinculum (1); ausente (0)

17 Armas costales de la valvas ausentes (0) presentes (1)

18. Anellus muy reducido (0); desarrollado (1)

19. Anellus en forma de "U" o bicircular (1); cuadrangular o subrectangular (0)

20. Proceso del anellus espiniforme (0), en forma de cuerno (1), subcuadrangular (2), espina laminar (3), barra (4) cinta (5)

21. Base del proceso del anellus no plegado (0), plegado (1)

22. Longitud del proceso del anellus igual o más corta que el uncus (0); más larga (1)

23. Proceso del anellus nace de la región anterolateral del anellus (1); posterolateral del anellus $(0)$

24. Superficie del proceso del anellus con cerdas (1), espinas (2), cerdas y espinas (3), glabra (0)

25. Proceso del anellus densamente cubierto de cerdas (1); cerdas escasas (0)

26. Cerdas del proceso de anellus en forma de mechón (1), cerdas sin forma de mechón (0)

27. Ápice del proceso del anellus terminado en espinas (3), apéndices digitiformes (2), cerdas (1), sin terminaciones especiales (0)

28. Cristae presente (1); ausente (0)

29. Con más de 50 cerdas en el cristae en cada lado (1); entre 3 y 50 cerdas (0)

30. Funda del aedeagus sin una proyección triangular o rectangular en el ápice posteroventral (1); con esta proyección (0)

31. Funda del aedeagus con una protuberancia en la zona media del vientre del aedeagus (1); ausente (0)

32. Vesica sin cornuti (1); con cornuti (0)

33. Espinas de la vesica dispuestas en hilera (1); en grupo o aisladas (0)

34. Hilera de espinas en la vesica forma un ángulo de $90^{\circ}$ (1); en línea recta (0)

35. Vesica con un grupo de espinas similares en tamaño (1), con un grupo pequeño de espinas en la base del grupo de espinas mayores (2); espinas no agrupadas $(0)$

36. Ductus bursae más corto que ancho o igual (1); más largo que ancho (0)

37. Corpus bursae más de dos veces más largo que las apófisis posteriores (0); dos veces más largo o menos (1)

38. Corpus bursae doblado hacia la derecha (1), recto (0)

39. Con un par de lóbulos donde el ductus burase se une con el ostium bursae (1), sin lóbulos (0).

40. Con estrías en la porción posterior del corpus bursae (1); sin ellas (0)

41. Con estrías en la porción anterior del corpus bursae (1); sin ellas (0)

42. Corpus bursae globoso (0), cilíndrico (1)

43. Signum ausente (1); presente (0)

44. Signum como barra esclerosada (1); redondo, estrellado o elíptico (0)

(1) y (2) estados derivados o apomórficos; (0) estado ancestral o plesiomórfico
En maculación (Fig. 2b), algunas especies se asemejan a taxa de otros géneros, así por ejemplo el patrón observado en E. agitata (mancha subtriangular formada por las bandas antemedial y medial) se encuentra en especies del género Psilaspilates (Parra 1999a), la naturaleza del proceso del anellus (ahusado y esclerosado en Psilaspilates) y la forma del gnathos (en forma de "V" en Psilaspilates) en la armadura genital del macho son caracteres que nos permiten diferenciar con claridad estos taxa.

Distribución. Género endémico de la zona en estudio, es el género con la distribución más amplia de la tribu, desde $\operatorname{los} 33^{\circ}$ a los $55^{\circ} \mathrm{S}$, y junto a Psilaspilates Butler alcanza el extremo austral de Chile. Su distribución sigue el bosque esclerófilo y templado del sur de Chile y el bosque templado frío de Nothofagus en el lado argentino.

Observaciones. Se remueve de la sinonimía a los géneros Incalvertia y Calvertia, inicialmente propuesta por Pitkin (2002) como sinónimos de Euclidiodes (ver más adelante las observaciones del género Incalvertia). Más comentarios sobre el género en el trabajo de Parra (1999b).

\section{Franciscoia Orfila y Schajovskoy, 1963}

Franciscoia Orfila y Schajovskoy 1963:3.

Franciscoia Orfila y Schajovskoy. Fletcher 1979: 88; Rindge 1986: 44.

Especie tipo: Franciscoia morenoi Orfila y Schajovskoy 1963:5. Por designación original.

El género es monotípico, fue revisado por Rindge (1986), por ello la información presentada aquí es restringida.

Diagnosis y monofilia. Se distingue de los demás géneros por su color castaño rojizo y por las bandas basal, antemedial, medial y postmedial castaño oscuras que cruzan las alas perpendicularmente (Fig. 2c), condición que se constituye en la autapomorfía que lo define.

En el macho la antena es simple, la tibia metatorácica no lleva el pincel de pelos, y en la genitalia (Figs. 7a-e) por la forma de barra del proceso del anellus y la presencia de microespinas en la región anterior y posterior de la barra esclerosada de la vesica, que lo diferencian de otros géneros que no presentan estas modificaciones.

Distribución. Género endémico para la zona en estudio. El registro más septentrional es Curicó (34 $30^{`} \mathrm{~S}$ ) y el más austral Osorno (40 30` S). En Argentina se tienen registros en Pucará y San Martín de los Andes. Se distribuye siguiendo la vegetación dominada por bosque esclerófilo, bosque templado y templado frío de Nothofagus.

Observaciones. Orfila y Schajovskoy (1963) indican que Franciscoia es un género muy próximo a Proteopharmacis, del que se distingue fundamentalmente por la coalescencia de las venas $\mathrm{Sc}$ y $\mathrm{R}_{1}$ en las alas anteriores. El análisis detallado de la venación alar realizado en este estudio, indica que esta coalescencia se presenta en ambos géneros y que la única diferencia evidente es la ausencia de la celda accesoria en Franciscoia a diferencia de Proteopharmacis. Los otros caracteres que permiten separar estos dos géneros son: el cornuti de la vesica (Fig. 7d), la forma de la genitalia de la 


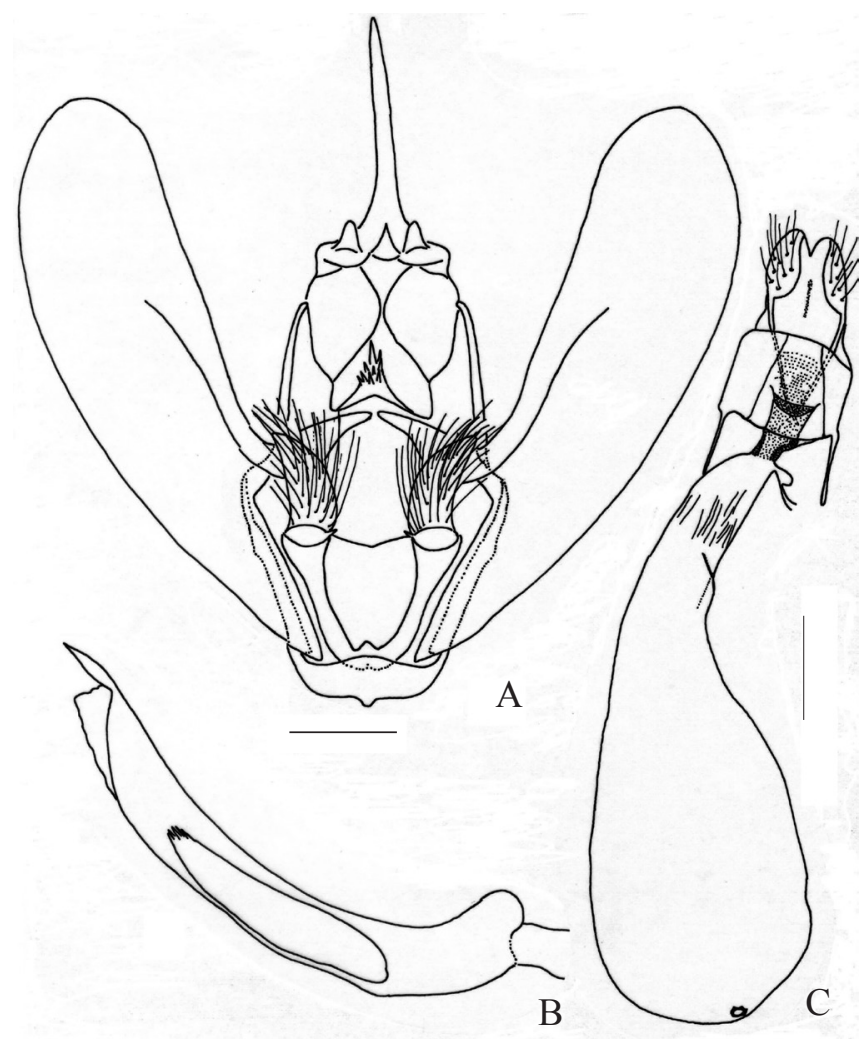

Fig. 11. Armaduras genitales del macho y hembra de Incalvertia valdiviana. a) genitalia del macho en vista ventral; b) aedeagus en vista lateral; y c) genitalia de la hembra en vista ventral. Escalas $0,25 \mathrm{~mm}$, figura c $1 \mathrm{~mm}$.

hembra (Fig. 7e) y la ausencia del pincel de pelos en la tibia metatorácica en el macho, entre otros.

\section{Franciscoia ediliae Parra sp. nov.} (Figs. $2 \mathrm{f}$ y $8 \mathrm{a}-\mathrm{d}$ )

Material tipo. HOLOTIPO, macho, Fundo Jauja, Prov. Malleco (IX Región de Chile), 23-VIII-1990, coll. C. Carrasco; ALOTIPO, hembra, mismos datos Holotipo (UCCC-MZUC). PARATIPOS: 3 machos, 23-VIII1990, 2 machos, 25-30-VII-1991, 2 machos, 20-30-VIII-1990; 3 machos, 23-VIII-1990 (MNHN), todos de Jauja, Prov. Malleco (IX Región de Chile), coll. C. Carrasco. (UCCC-MZUC)

Diagnosis. La especie posee un patrón de maculación muy similar a F. morenoi Orfila y Schajovskoy, aunque los colores aquí son más oscuros. Las áreas rojizas aparecen abigarradas de manchas oscuras. Franciscoia ediliae n. sp. difiere de $F$. morenoi principalmente en las características de las antenas del macho, gnathos, proceso del anellus, espinas en el tercer segmento abdominal y en la hembra por la presencia de estrías en el ductus bursae. En ediliae la antena del macho es pectinada, gnathos en forma de "U", proceso del anellus en forma de cinta muy esclerosada y tercer segmento abdominal del macho con una fila de cerdas ventrales. Hembra con estrías transversales en el ductus bursae. En morenoi la antena del macho simple, gnathos en forma de "V", proceso del anellus en forma de barra, esclerosado con cerdas en su borde externo. Hembra con ductus bursae sin estrías, muy esclerosado.
Descripción. Aspecto general como lo muestra la figura 2f.

Macho. Alas anteriores: superficie dorsal castaño rojiza uniforme; bandas antemedial y postmedial marcadas por una línea arqueada y fina, de color negro, la postmedial forma dos ángulos, uno en el margen costal y el otro sobre $\mathrm{R}_{5} \mathrm{y} \mathrm{M}_{1}$, a la altura de las venas anales tiende a converger con la banda medial; banda medial subrecta, tres veces más ancha que las otras bandas, castaño rojiza oscura; mancha discal ausente. Superficie ventral similar a la dorsal, los colores son mucho más débiles y tienen un cierto tono gris. Alas posteriores: superficie dorsal rosácea; bandas medial y extradiscal representadas por líneas más oscuras; mancha discal ausente. Superficie ventral mucho más clara que la dorsal; bandas casi imperceptibles.

Hembra. Similar al macho.

Longitud de las alas anteriores: macho, 14 a $15 \mathrm{~mm}$; hembra $16 \mathrm{~mm}$.

Genitalia del macho (Figs. 8a-c). Uncus curvo, simple, ápice agudo; socius subcircular, reducido; gnathos en forma de "U", cubierto de numerosas espinas cortas y fuertes en la región media altamente esclerosada (Fig. 8b); valvas simples, subrectangulares, subiguales al largo del proceso del anellus; anellus reducido, subrectangular; proceso del anellus muy esclerosado, plano, 16 veces más largo que su parte más ancha, sus dos tercios anteriores anchos, tercio posterior estrecho en su base para luego ensancharse y terminar en una punta redonda, superficie cubierta de cerdas dispersas en su región media; saccus-vinculum redondo (semicírculo) (Fig. 8a). Aedeagus (Fig. 8c) curvo ventralmente, levemente más

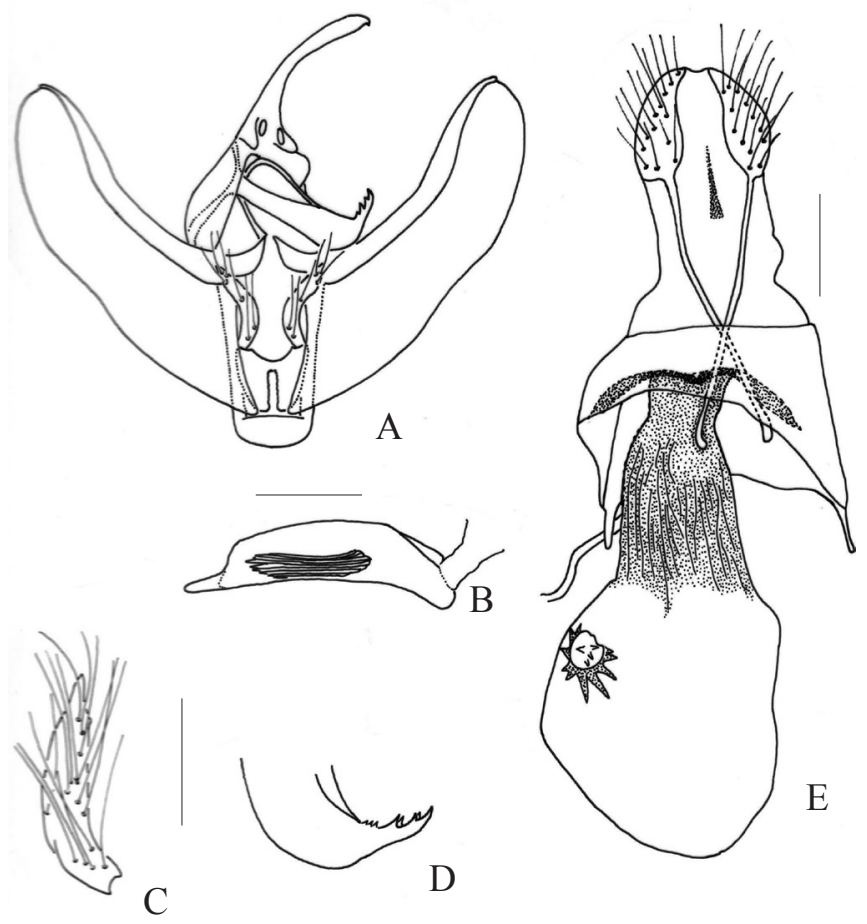

Fig. 12. Armaduras genitales del macho y hembra de Lacaria araucanaria. a) genitalia del macho en vista ventral; b) aedeagus en vista lateral; c) proceso del anellus; d) extremo del gnathos; y e) genitalia de la hembra en vista ventral. Escalas $0,25 \mathrm{~mm}$, figura e $0,5 \mathrm{~mm}$. 


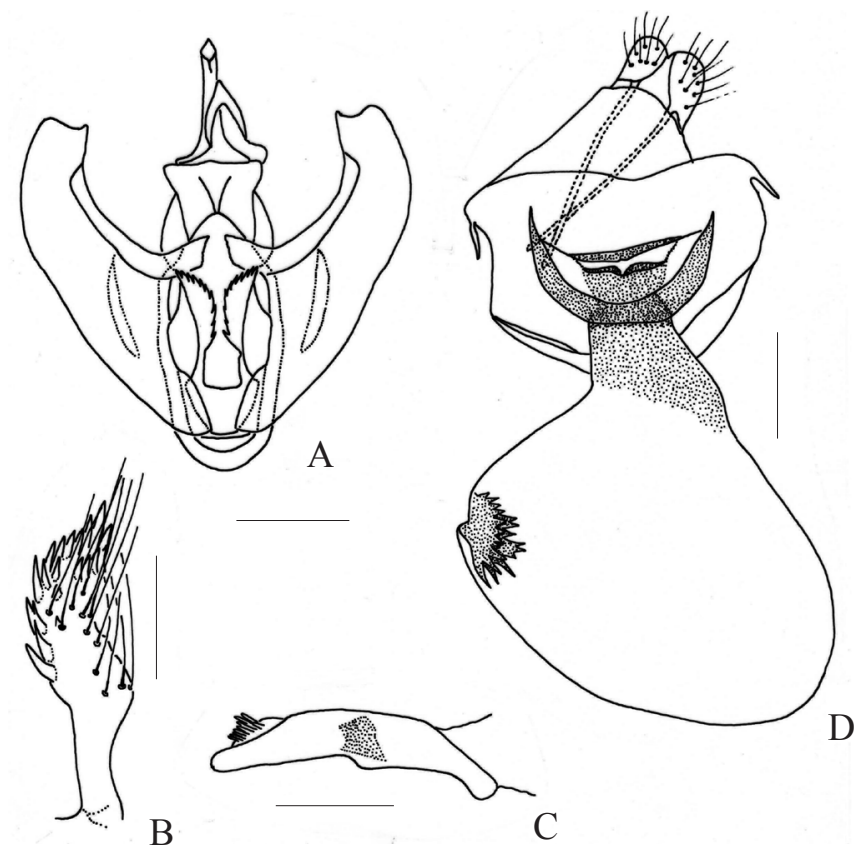

Fig. 13. Armaduras genitales del macho y hembra de Lacaria orfilai. a) genitalia del macho en vista ventral; b) proceso del anellus; c) aedeagus en vista lateral; y d) genitalia de la hembra en vista ventral. Escalas $0,25 \mathrm{~mm}$, figura d $0,5 \mathrm{~mm}$.

largo que la valva, 16 veces más largo que ancho; vesica con cuatro espinas largas y delgadas, que ocupan la tercera parte de la longitud total del aedeagus.

Genitalia de la hembra (Figs. 8d). Corpus bursae esférico en su mitad anterior, membranoso, mitad posterior subcónica, esclerosada y estriada; signum en la región posterior del corpus, semicircular y estrellado; ductus seminalis nace ventralmente de un saco cónico entre el corpus y el ductus bursae; ductus bursae cuatro veces más largo que ancho, con estrías transversales, esclerosado, en su unión con el corpus bursae levemente hinchado ventralmente; esterigma esclerosado; apófisis posteriores dos veces más largas que las anteriores.

Distribución. La distribución esta restringida sólo a la localidad de recolección de la serie tipo, Fundo Jauja, cerca de las Termas de Pemehue (Provincia de Malleco) $\left(38^{\circ} 04^{`} \mathrm{~S}\right.$ $\left.-71^{\circ} 55^{\circ} \mathrm{O}\right)$.

Etimología. Esta especie está dedicada a la esposa del Dr. Luis E. Parra.

\section{Tanagrida Butler, 1882}

Tanagridia Butler, 1882: 425.

Guara Rindge 1986: 36 (Sinonimia establecida por Pitkin, 2002:197).

Callemo Rindge 1986: 29 (Sinonimia establecida por Pitkin, 2002:197).

Especies tipos: Tanagridia fusca Butler 1882: 425. Por designación original. Guara rhaphis Rindge 1986:38. Por designación original.

Callemo monotonos Rindge 1986:30. Por designación original.

El género, el cual incluye dos especies, está descrito por Butler (1882) y fue redescrito por Pitkin (2002).

Diagnosis y monofilia. Se distingue de los demás géneros de la tribu en: macho con antenas simples, no hay pincel de pelos en la tibia metatorácica ni cerdas en el tercer segmento abdominal; genitalia del macho (Fig. 9a-d) las valvas con válvula, están ampliamente unidas al saccus-vinculum y tienen un proceso costal; proceso del anellus terminado en cuatro apéndices digitiformes largos en su región apical; y la vesica carece de cornuti (Fig. 9d), estos caracteres representan las autopomorfías que caracterizan al género. Rindge (1986) señala que Tanagridia se caracteriza por la presencia de un signum en forma de una faja esclerosada en el corpus bursae de la hembra.

Su maculación se asemeja bastante a algunas especies de Euclidiodes, pero en este caso la figura subtriangular está ubicada en la zona externa del ala y la arista se encuentra en el ápice de la misma (Fig. 2d).

Distribución. Género endémico de la zona en estudio, su registro más septentrional es Cautín $\left(38^{\circ} \mathrm{S}\right)$ y el más austral Chiloé $\left(43^{\circ} \mathrm{S}\right)$. Su distribución incluye el bosque templado del tipo valdiviano nordpatagónico.

Observaciones. La identificación de este género y sus dos especies se basan en la publicación del trabajo de Rindge (1986) y Pitkin (2002). Los tipos no pudieron ser estudiados.

A pesar de haber recolectado en localidades próximas a la típica, no se ha capturado ningún ejemplar de esta especie. Puede tratarse de una especie muy poco abundante. Sólo se ha estudiado un macho, por lo que los datos de la hembra corresponden a las observaciones de Rindge (1986).

\section{Rhinoligia Warren, 1895}

Rhinoligia Warren 1895:159.

Rhinoligia Warren. Fletcher 1979: 182.

Especie tipo: Rhinodia biocellata Felder y Rogenhofer 1875: pl. 129, fig. 14. Designada por Warren 1895: 159.

Descripción. La apariencia general de la polilla es mostrada en la figura $3 \mathrm{~h}$. Polillas de tamaño mediano, la longitud de las alas anteriores $17 \mathrm{~mm}$.

Frente con un penacho de escamas en su porción ventral; antenas simples en ambos sexos; segmento medio del palpo labial tres veces más largo que el distal. Alas anteriores castaño rojizas, con dos manchas blancas en el margen anal. Alas posteriores blancas con una mancha blanca bordeada de negro en el margen anal. Venación alas anteriores: con celda accesoria. Venación alas posteriores: $\mathrm{Sc}+\mathrm{Rs}$ unidas cerca de la base de la celda discal durante una longitud cercana a 1/3 de la longitud de ésta; $M_{2}$ representada por un pliegue, no tubular. Patas: tibia y tarsos anillados por franjas castaño oscuras y claras; tibia metatorácica del macho con un pincel de pelos; fórmula tibial 0-2-4. Abdomen concoloro con las alas, con aproximadamente 33 cerdas en el lado ventral del tercer segmento del macho.

Genitalia del macho (Figs. 10a-b). Proceso del anellus membranoso cubierto de cerdas. Esta especie tiene un proceso del anellus similar al de Incalvertia valdiviana (B.-C.) comb. nov., pero difiere de ella en el patrón de maculación y en el tipo de armadura genital de la hembra.

Genitalia de la hembra (Figs. 10c). Corpus bursae esférico 


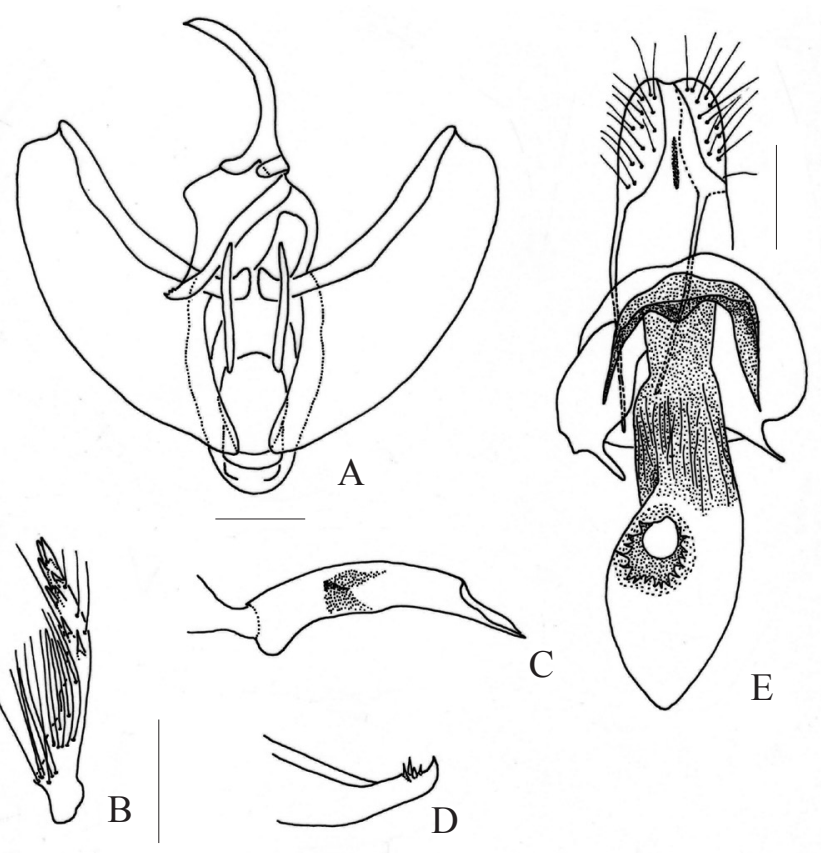

Fig. 14. Armaduras genitales del macho y hembra de Lacaria picuncharia. a) genitalia del macho en vista ventral; b) proceso del anellus; c) aedeagus en vista lateral; d) extremo del gnathos; y e) genitalia de la hembra en vista ventral. Escalas $0,25 \mathrm{~mm}$, figura e $0,5 \mathrm{~mm}$.

en su tercio anterior y cilíndrico y esclerosado en su porción posterior.

Diagnosis y monofilia. Genitalia del macho con el proceso del anellus membranoso cubierto de cerdas. Genitalia de la hembra, corpus bursae esférico en su tercio anterior y cilíndrico y esclerosado en su región posterior. Las alas anteriores de esta especie son castaño rojizas, en el margen anal lleva dos máculas blancas bordeadas de negro.

Distribución. Se encuentra sólo en Chile, su registro más septentrional es Concepción ( $\left.36^{\circ} 30^{`} \mathrm{~S}\right)$ y el más austral es Araucanía en la zona de Temuco. Distribución asociada al bosque templado del sur de Chile.

\section{Incalvertia Rindge, 1986}

Calvertia Warren 1908:106, nec Calvertia Bourguinat 1880: 55. Calvertia Warren. Fletcher 1979:80; Rindge 1983:159.

Incalvertia Rindge 1986:63 [nombre de reeemplazo para Calvertia]

Especie tipo: Calvertia fumipennis Warren 1908:107. Por monotipia.

Descripción. La apariencia general de la polilla es mostrada en la figura 2e. Polillas medianas a grandes, la longitud del ala anterior varía entre 18 y $21 \mathrm{~mm}$.

Antena simple en ambos sexos; palpo labial, segmento medio dos veces más largo que el distal. Superficie dorsal de las alas anteriores en distintas intensidades del color castaño: claro, oscuro, amarillento, anaranjado; bandas antemedial, medial y postmedial castaño oscuras. Superficie ventral castaño anaranjadas, maculación débil. Alas posteriores: similar a las anteriores en coloración, banda medial y mancha discal presente. Superficie ventral similar a las alas anteriores.
Venación alas anteriores: sin celda accesoria. Venación alas posteriores: $\mathrm{Sc}+\mathrm{Rs}$ unidas cerca de la base, alrededor de la mitad de la longitud de la celda discal; $\mathrm{M}_{2}$ representada por un pliegue, no tubular. Patas: castaño oscuras abigarradas por escamas claras en su lado externo, amarillentas en el interno; pincel de pelos en la tibia posterior del macho; formula tibial 0-2-4. Abdomen concoloro con las alas; aproximadamente con 25 cerdas en el lado ventral del tercer segmento en el macho.

Genitalia del macho (Figs. 11a-b). Cristae presente; proceso del anellus membranoso y cubierto densamente de cerdas.

Genitalia de la hembra (Figs. 11c). Corpus bursae subpiriforme; signum en la región anterior del corpus.

Diagnosis y monofilia. La única especie de este género se parece externamente a las especies de Catophoenissa por maculación y tamaño, pero a diferencia de éstas, las antenas del macho son simples; en la genitalia del macho difiere en la presencia del cristae y en que el proceso del anellus es membranoso y está densamente cubierto de cerdas; en la genitalia de la hembra con el signum está ubicado en la región anterior del corpus bursae.

Distribución. Género endémico de Chile, su registro más septentrional es Cauquenes ( $\left(35^{\circ} 30^{`} \mathrm{~S}\right)$ y el más austral Valdivia $\left(40^{\circ} \mathrm{S}\right)$. Se distribuye en los bosques esclerófilos y templados de Chile Central.

Observaciones. En el uso del nombre Calvertia se incurrió en homonimia, pues este nombre estaba ocupado por Calvertia Bourguignat, 1880 (Mollusca). Rindge (1986), con estos datos, propone Incalvertia para reemplazar el nombre de Calvertia.

Fletcher (1979) coloca a Calvertia como sinónimo de Euclidiodes Warren. Sin embargo, al examinar las especies tipo de ambos géneros se constató que ambas no son congenéricas, por lo que Calvertia se revierte al estatus de género.

Bartlett-Calvert (1893) describe Boarmia valdiviana e ilustra un adulto. En 1908, Warren sobre un ejemplar macho le dedica Calvertia (nuevo género) al primer autor mencionado y dice que la especie Asestra izquierdii BartlettCalvert (1893) puede ser referida a este género. Esta opinión es rechazada ya que un análisis de la morfología externa e interna de ejemplares de esta especie, permite concluir que no es congenérica con el taxon tratado aquí ni puede ser incluida en los Lithinini, más bien pertenece a los Nacophorini.

En 1983, Rindge coloca en sinonimia a Talca catophoenissoides Angulo. Esta opinión se basa en la comparación que Rindge hizo de ejemplares con la publicación de Angulo. La revisión del material tipo de T. cataphoenissoides nos muestra, que efectivamente los caracteres, tanto externos como de su genitalia, se corresponden con los diagnósticos de $B$. valdiviana.

La identificación de C. fumipennis se basa en la descripción e ilustración presentada por Rindge (1986) gracias a una minuciosa descripción de ella. Rindge (1986) considera a C.fumipennis como sinónimo junior de $B$. valdiviana.

El material tipo de B. valdiviana depositado en el Museo Nacional de Historia Natural, Santiago (MNHN) está 
Tabla II. Matriz de los estados de caracteres polarizados para los géneros de Lithinini, basada en la Tabla I, para construir el cladograma.

\begin{tabular}{|c|c|c|c|c|c|c|c|c|c|c|c|}
\hline \multirow{2}{*}{$\begin{array}{c}\text { Taxa } \\
\text { Catophoenissa }\end{array}$} & \multicolumn{11}{|c|}{ Caracteres } \\
\hline & 00000 & 00000 & 00000 & 00000 & 00000 & 00000 & 00000 & 00000 & 00000 & 00000 & 0000 \\
\hline Acauro & 10011 & 10001 & 11100 & 00012 & 00012 & 00010 & -0101 & -0101 & 000-0 & 10001 & 0000 \\
\hline Asestra & 10011 & 00001 & 00000 & 00011 & 00011 & 00011 & 10101 & 10101 & $000-0$ & 11001 & 0000 \\
\hline Calta & 01011 & 00001 & 00000 & 00103 & 00103 & $0100-$ & -1101 & -1101 & 00110 & 10001 & $011-$ \\
\hline Euclidiodes & 11011 & 10001 & 11200 & 00011 & 00011 & 00010 & -0101 & -0101 & $000-1$ & 10001 & 0000 \\
\hline Franciscoia & 10110 & 10101 & 00000 & 00103 & 00103 & $0100-$ & -0111 & -0111 & 000-0 & 00001 & 0100 \\
\hline Incalvertia & 10011 & $10 ? 01$ & 11200 & 00001 & 00001 & 00111 & -0111 & -0111 & $000-0$ & 10001 & 0000 \\
\hline Lacaria & 20011 & 10001 & 11010 & 00011 & 00011 & 00010 & -0101 & -0101 & $100-0$ & 11001 & 0000 \\
\hline Laneco & 11011 & 10001 & 10000 & 00001 & 00001 & 00010 & -0101 & -0101 & $000-0$ & 10001 & $001-$ \\
\hline Maeandrogonaria & 11111 & 00011 & 12000 & 00011 & 00011 & 00010 & -0101 & -0101 & $000-0$ & 10011 & $001-$ \\
\hline Martindoelloia & 11111 & 00201 & 10000 & 00001 & 00001 & $0000-$ & -1101 & -1101 & $000-0$ & 10001 & 0001 \\
\hline Nucara & 20011 & $11 ? 01$ & 12000 & 00011 & 00011 & 10011 & -3101 & -3101 & $000-0$ & 10001 & 0000 \\
\hline Odontothera & 10011 & 00001 & 11000 & 00011 & 00011 & $0002-$ & -0101 & -0101 & 00100 & 10000 & $011-$ \\
\hline Proteopharmacis & 11011 & 00001 & 11000 & 00104 & 00104 & $0100-$ & -0111 & -0111 & 00100 & 00100 & $101-$ \\
\hline Psilaspilates & 21011 & $11 ? 01$ & 11000 & 00011 & 00011 & $0000-$ & -0101 & -0101 & $000-2$ & 10001 & 0000 \\
\hline Rhinoligia & 10111 & $01 ? 01$ & 11000 & 00001 & 00001 & 00111 & -0111 & -0111 & $000-0$ & 10001 & 0000 \\
\hline Tanagridia & 11110 & 00001 & 00001 & 11003 & 11003 & $0000-$ & -2101 & -2101 & $01--$ & 00000 & $001-$ \\
\hline
\end{tabular}

representado sólo por un ejemplar Sintipo de la serie original (los otros perdidos), por lo que la identificación de esta especie se basó en este ejemplar, en la descripción original $\mathrm{y}$ en la representación ilustrada del adulto (Bartlett-Calvert 1893). Este ejemplar Sintipo se designa aquí como Lectotipo y queda depositado en MNHN (ver material tipo y material examinado en anexo 1).

Al revisar los ejemplares y la armadura genital de todas las especies comprometidas, se concluye que las especies descritas por Warren (1908) y Angulo (1977) corresponden más bien a sinónimos junior de B. valdiviana, por lo que todos los nombres posteriores son colocados en sinonimia.

\section{Lacaria Orfila y Schajovskoy, 1959}

Lacaria Orfila y Schajovskoy 1959:198.

Lacaria Orfila y Schajovskoy. Fletcher 1979:111; Rindge 1986:42.

Especie tipo: Lacaria araucanaria Orfila y Schajovskoy 1959:198. Por designación original.

El género, el cual incluye 7 especies, fue revisado por Rindge (1986), por ello la información presentada aquí es restringida.

Diagnosis y monofilia. Este género se distingue fácilmente de los otros de la tribu, por las antenas serradas de los machos y el patrón de maculación de las diferentes especies. Las autapomorfías que definen el género se encuentran en la genitalia del macho, éstas son: una extensión apical corta en la costa de las valvas; el proceso del anellus es variable pero único dentro de los Lithinini (ver figuras 12a-e, 13a-c, 14ad y $15 \mathrm{a}-\mathrm{c}$ ), está cubierto de espinas y cerdas; y el aedeagus posee una protuberancia en la región ventral de la funda. La genitalia de la hembra es pequeña, el corpus bursae amplio y grande, membranoso, signum estrellado, asimétrico (ver figuras 12e, 13d, 14e y 15d).

Distribución. Género endémico de la zona en estudio, se encuentra distribuido entre $\operatorname{los} 36^{\circ} 30^{\prime}$ y aproximadamente los $40^{\circ} \mathrm{S}$. La especie L. araucanaria se encuentra sólo en
Argentina, en el límite norte de la Estepa Patagónica (bosque templado frío), las otras especies habitan en ambos lados de la Cordillera de los Andes. Como en muchas otras especies, el género tiene su distribución asociada al bosque templado del lado chileno y argentino (Parque Nacional Lanín, Neuquén).

Observaciones. Además de la especie tipo, L. araucanaria, otras dos especies aparecen citadas en el trabajo de Orfila y Schajovskoy (1959), Lacaria aczeli y Lacaria sperryi. Estas dos últimas especies no pudieron ser revisadas personalmente, ya que el material tipo no pudo ser consultado y en las colecciones estudiadas no se encontraron ejemplares de estas especies.

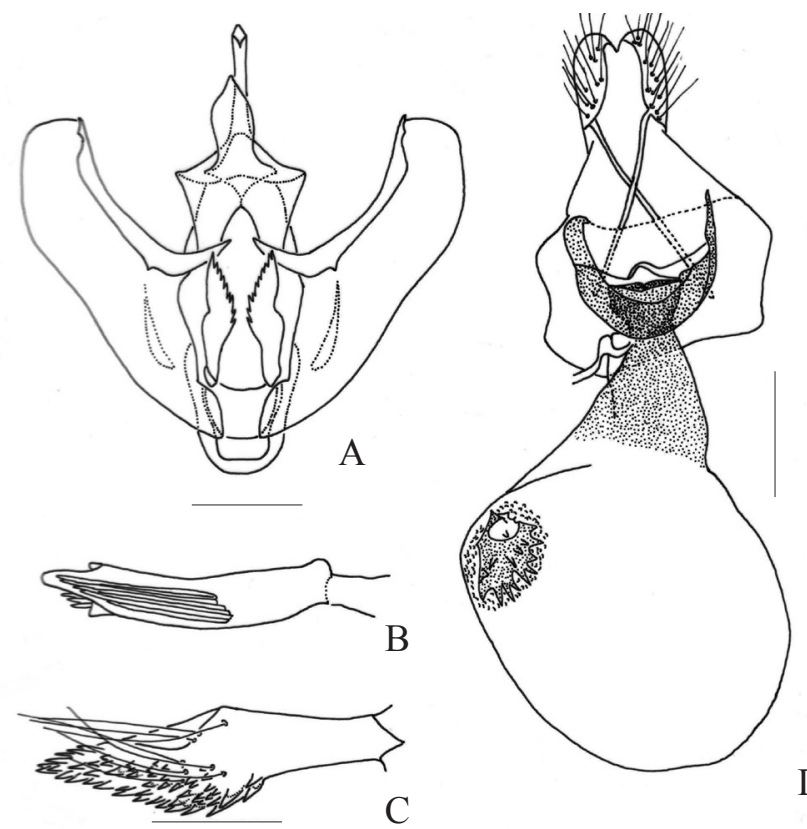

Fig. 15. Armaduras genitales del macho y hembra de Lacaria schajovskoyi. a) genitalia del macho en vista ventral; b) aedeagus en vista lateral; c) proceso del anellus; y d) genitalia de la hembra en vista ventral. Escalas 0,25 $\mathrm{mm}$, figura d $0,5 \mathrm{~mm}$. 

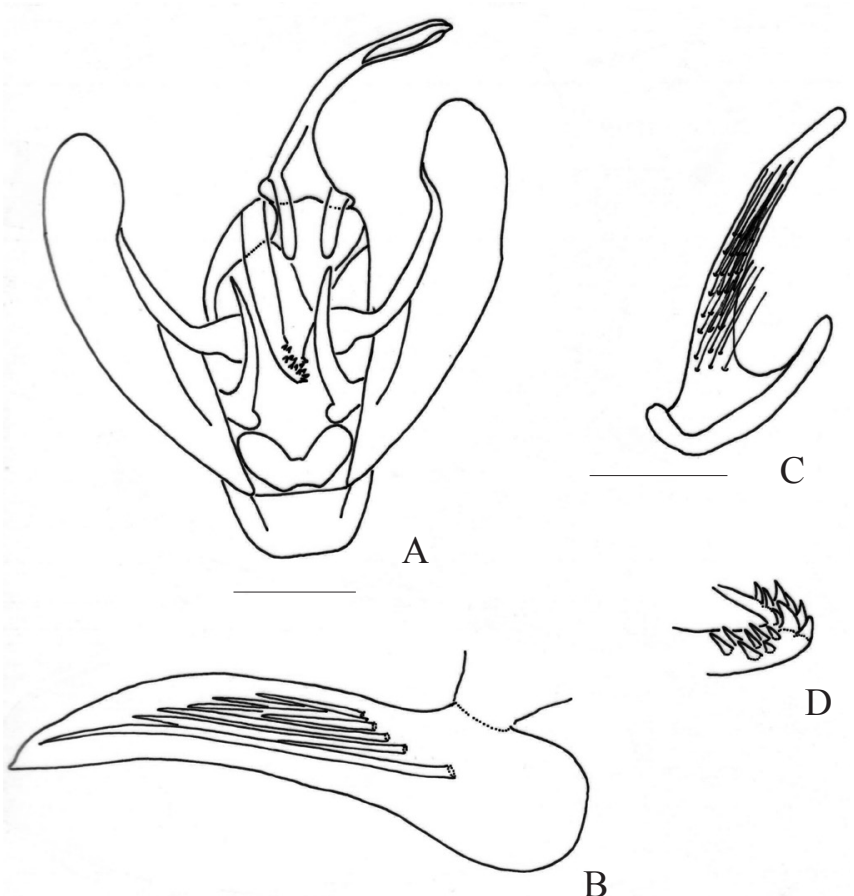

$\mathrm{D}$

Fig. 16. Armaduras genital del macho de Maeandrogonaria valentina. a) genitalia del macho en vista ventral; b) aedeagus en vista lateral; c) proceso del anellus; y d) extremo del gnathos. Escala 0,25 mm.

Cuando se analiza la forma y estructura del proceso del anellus, según las figuras originales de Orfila y Schajovskoy (op. cit.), L. sperryi resulta mucho más cercana a $L$. orfilai y $L$. schajovskoyi, en cambio L. aczeli lo es más a L. araucanaria y L. picuncharia. Seguramente un análisis más detallado producto de un muestreo más intensivo, dará mayores luces sobre este género, pues las especies entre sí son muy semejantes en cuanto a patrón de maculación. Seguramente esta condición indujo a Sperry (1954) a describir Casbia schajovskoyi con una serie tipo que según Rindge (1986), estaba conformada por más de una especie, incluyendo algunos paratipos que en realidad son individuos de $L$. araucanaria. Rindge (1986) al comparar los ejemplares tipos (Holo y Alotipo) de Casbia schajovskoyi (en AMNH) con las ilustraciones de Orfila y Schajovskoy (1959) para L. monrosi, encontró que esta última especie es sinónimo junior de la especie descrita por Sperry (1954). En este trabajo se asume esta observación y L. monrosi es colocada en sinonimia de la primera.

Rindge (1986) indica que sólo L. picuncharia está en lado argentino y chileno y que al menos seis especies nuevas surgen al revisar ejemplares de la vertiente chilena de la Cordillera de los Andes. Sin embargo, las polillas examinadas provenientes tanto de recolección en el campo como de colecciones de museos nos revelan que prácticamente todas las especies comparten la misma zona de distribución. $L$. picuncharia no es la única especie compartida con Argentina, las especies conocidas para Chile también se presentan en el territorio argentino no encontrándose ningún taxon nuevo.

La identificación de las especies puede resultar difícil si sólo se comparan patrones de maculación (ver figuras $2 \mathrm{~g}-\mathrm{h}$ y $3 \mathrm{a}-\mathrm{b})$, un análisis de la armadura genital es necesario para asignar uno o varios ejemplares a una especie determinada.

\section{Maeandrogonaria Butler, 1893}

Maeandrogonaria Butler 1893:460.

Maeandrogonaria Butler. Fletcher 1979:122.

Meandrogonia Butler. Angulo y Casanueva 1981:29. Ortografía incorrecta subsiguiente.

Huechulafquenia Orfila y Schajovskoy 1964:26.

Huechulafquenia Orfila y Schajovskoy. Fletcher 1979:102; Rindge 1986:53.

Especie tipo: Maeandrogonaria valentina Butler 1893:460, para Maeandrogonaria Butler 1893:460, por monotipia.

Huechulafquenia formosa Orfila y Schajovskoy 1964:28, para Huechulafquenia designada por Orfila y Schajovskoy 1964:28.

Descripción. La apariencia general de la polilla es mostrada en la figura 3c. Polillas de tamaño mediano, la longitud del ala anterior varía entre 14 y $17 \mathrm{~mm}$.

Frente con un penacho de escamas en su porción ventral; antenas simples en ambos sexos; segmento medio del palpo labial dos veces más largo que el distal. Las alas anteriores son castaño anaranjadas con áreas claras, en toda la superficie destacan las venas por su color castaño anaranjado más oscuro; bandas antemedial, medial y postmedial representadas. Superficie ventral prácticamente similar, la región costal más intensa en maculación que la región del margen anal. Alas posteriores blancas, márgenes anal y externo castaño anaranjados; banda extradiscal castaño oscura. Superficie ventral abigarrada por escamas castaño anaranjadas; bandas bien marcadas. Venación alas anteriores: sin celda accesoria. Venación alas posteriores: $\mathrm{Sc}+\mathrm{Rs}$ paralelas; vena $\mathrm{M}_{2}$ representada por un pliegue, no tubular. Patas: blancas con manchas castaño rojizas en su lado externo, amarillentas en el interno; tibia metatorácica del macho con pincel de pelos; fórmula tibial 0-2-4. Abdomen concoloro a las alas anteriores, con aproximadamente 38 cerdas en el lado ventral del tercer segmento del macho.

Genitalia del macho (Figs. 16a-d). Anellus muy desarrollado, subrectangular; proceso del anellus ahusado, cubierto de cerdas.

Genitalia de la hembra. Corpus bursae asimétrico, esclerosado en la región dorsal posterior (Rindge 1986).

Diagnosis y monofilia. Este género se distingue por la forma de las alas anteriores, más largas entre la costa y la vena $M_{1}$ que desde $M_{1}$ hacia el margen anal, muy onduladas en su margen externo. Las alas son castaño anaranjadas, con áreas claras en la zona media y con las venas distintas por su color anaranjado. En la armadura genital se diferencia de los otros géneros por poseer, en el macho, un proceso de anellus ahusado, muy esclerosado, cubierto de cerdas; y en la hembra por poseer un corpus bursae asimétrico. La presencia de una fóvea en las alas anteriores del macho y de un par de lóbulos ubicados en donde se une el ductus bursae con el ostium bursae, se constituyen en las autapomorfías que definen el género.

Distribución. Género endémico en la zona en estudio, se distribuye en Chile y Argentina; su registro más septentrional 


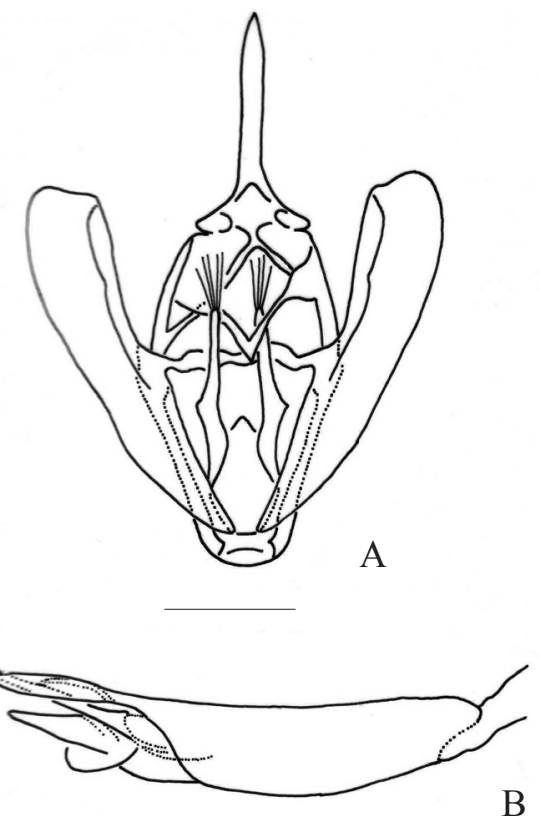

Fig. 17. Armadura genital del macho de Martindoelloia juradoi. a) genitalia del macho en vista ventral; b) aedeagus en vista lateral; y c) proceso del anellus. Escala $0,25 \mathrm{~mm}$.

es Talca $\left(35^{\circ} 30^{`} \mathrm{~S}\right)$ y el más austral Isla Guafo $\left(43^{\circ} 30^{`} \mathrm{~S}\right)$, en Argentina en Neuquén y Río Negro. Su distribución está asociada al bosque templado y esclerófilo.

Observaciones. Orfila y Schajovskoy (1964) describieron un género y especie nuevos con material recolectado en Argentina. Pitkin (2002) incluye la especie formosa Orfila \& Schajovskoy como válida para el género Maeandrogonaria. En el estudio del material existente en el BMNH se encontró que la especie Maeandrogonaria valentina Butler es el sinónimo senior de Huechulafquenia formosa Orfila y Schajovskoy. Esta afirmación se basa tanto en el estudio del material tipo de la primera, como en el de un paratipo de la segunda. Por orden de prioridad se incluye a esta última en sinonimia de la especie descrita por Butler (1893).

\section{Martindoelloia Orfila y Schajovskoy, 1963}

Martindoelloia Orfila y Schajovskoy 1963:1.

Martindoelloia Orfila y Schajovskoy. Fletcher 1979:123; Rindge 1986:33.

Especie tipo: Martindoelloia juradoi Orfila y Schajovskoy 1963:2. Por designación original.

El género, el cual incluye una especie, fue revisado por Rindge (1986), por ello la información presentada aquí es restringida.

Diagnosis y monofilia. Las siguientes características permiten separar fácilmente este género de los otros pertenecientes a esta tribu. Las alas anteriores tienen un ápice atenuado y una proyección en la zona de la vena $\mathrm{M}_{3}$, entre el ápice y esta vena el ala es cóncava; la banda postmedial separa en dos zonas el ala, una castaño rojiza oscura y la otra clara (Fig. 3d). La genitalia del macho tiene el proceso del anellus elongado, delgado, en forma de barra, con cerdas en su región apical (17a-c). Genitalia de la hembra con el corpus bursae elongado, membranoso; signum delgado, recto y sin dientes (Rindge 1986). La presencia de dos bandas transversales en las alas y el signum en forma de una barra esclerosada constituyen las autapomorfías del género.

Distribución. Se encuentra distribuida en Chile y Argentina. Su registro más septentrional es Curicó ( $\left.34^{\circ} 30^{\prime} \mathrm{S}\right)$ y el más austral Chiloé (aproximadamente $43^{\circ} \mathrm{S}$ ). En territorio Argentino sólo es conocido de la región andina de Neuquén. La distribución coincide con los bosques esclerófilos y templados, este último en Chile y Argentina.

Observaciones. Orfila y Schajovskoy (1963) dicen que este género es muy próximo a Proteopharmacis Warren, y que se diferencian porque las venas Rs y M1 de las alas anteriores nacen separadas. Se trata sin duda de un error, seguramente ellos se referían a las venas Sc y Rs de las alas posteriores.

A pesar de contar con una hembra, no fue posible obtener su genitalia porque el abdomen está deteriorado. Para mayor referencia sobre estas estructuras ver las descripciones de Orfila y Schajovskoy (1963) y Rindge (1986), autores de los que se ha tomado la diagnosis de la hembra.

\section{Nucara Rindge, 1986}

Nucara Rindge 1986:40.

Especie tipo: Nucara recurva Rindge 1986:41. Por designación original.

El género, el cual incluye una especie, fue revisado por Rindge (1986), por ello la información presentada aquí es restringida.

Diagnosis y monofilia. La especie de este género, al igual que las de Lacaria y Psilaspilates, tienen las antenas serradas en el macho. Se distingue de éstos, porque en la genitalia del macho el proceso del anellus es una estructura larga y curvada hacia fuera, cubierta de cerdas (Fig. 18a-d); y en la hembra el corpus bursae es subpiriforme, con la región anterior membranosa y con un pequeño signum estrellado en su región ventral (Fig. 18e). La presencia de espinas en el ápice del anellus más el plegamiento de la base del proceso del anellus constituyen las autapomorfías del género.

Esta especie se distingue fácilmente de las otras especies de Lithinini, porque las alas anteriores llevan una mancha triangular castaño oscura en la zona media de la región costal (Fig. 3e).

Distribución. Se encuentra en Chile y Argentina, su registro más septentrional es Valparaíso $\left(33^{\circ} \mathrm{S}\right)$ y el más austral es Pucoihue (aproximadamente $40^{\circ} 30^{`} \mathrm{~S}$ ). Su distribución está asociada a bosque esclerófilo, templado y templado frío de Nothofagus y a la estepa Patagónica.

Observaciones. La identificación de la especie se basa en el trabajo original de Rindge (1986) y el material tipo no pudo ser examinado.

\section{Odontothera Butler, 1882}

Odontothera Butler 1882:409.

Odontothera Butler. Rindge 1986:25.

Yalpa Rindge 1986:22 (sinonimía establecida por Pitkin, 2002:195).

Especies tipos: Odontothera virescens Butler 1882:409, para Odontothera; designada por Fletcher 1979:144.

Yalpa dalcahue Rindge 1986:24, para Yalpa; designada por Rindge 1986:23. 


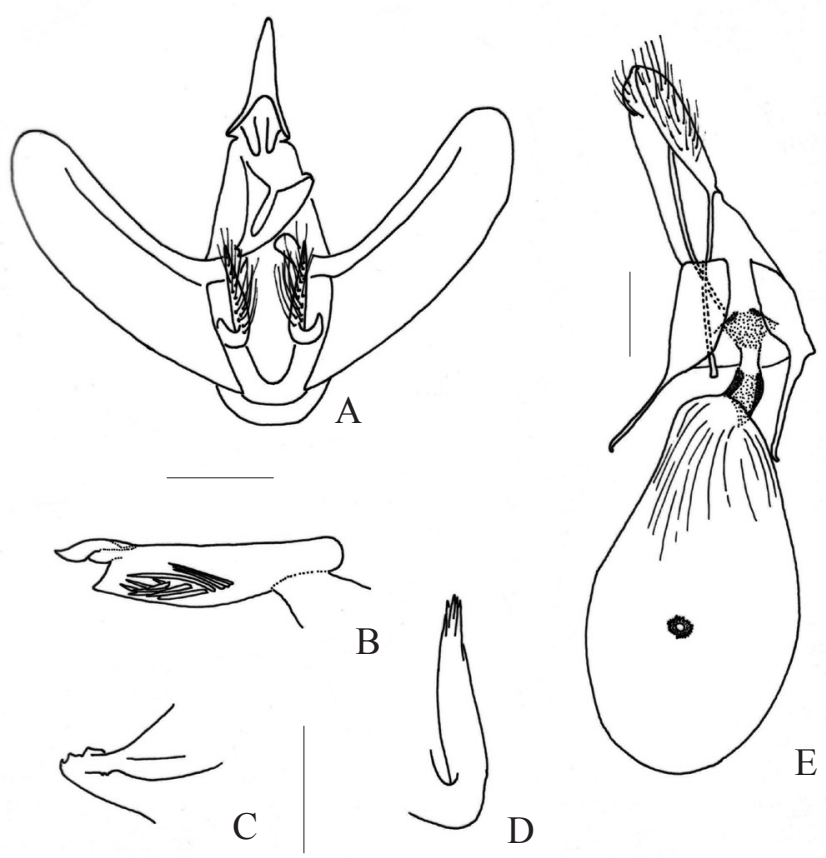

Fig. 18. Armaduras genitales del macho y hembra de Nucara recurva. a) genitalia del macho en vista ventral; b) aedeagus en vista lateral; c) extremo del gnathos; d) proceso del anellus; y e) genitalia de la hembra en vista ventral. Escalas $0,25 \mathrm{~mm}$, figura e $0,5 \mathrm{~mm}$.

Descripción. La apariencia general de la polilla es mostrada en la figura 3f. Polillas de tamaño mediano, la longitud del ala anterior varía entre 16 y $18 \mathrm{~mm}$.

Antena simple en ambos sexos; segmento medio del palpo labial dos veces más largo que el distal. Superficie dorsal de las alas abigarrada por manchas castaño oscuras, grises, amarillas verdosas; bandas antemedial, postmedial y subterminal marcadas. Superficie ventral más pálida, las manchas están marcadas pero débilmente. Alas posteriores: superficies dorsal y ventral blanco sucias. Venación de las alas anteriores: $\mathrm{Sc}$ y $\mathrm{R}_{1}$ unidas en un punto al término de la

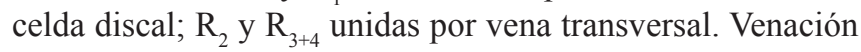
alas posteriores: $\mathrm{Sc}+\mathrm{Rs}$ unidas por una distancia cerca de la mitad de la celda discal; $M_{2}$ representada por un pliegue, no tubular. Patas: tibias y tarsos anillados por franjas castaño oscuras y claras; tibias metatorácicas del macho con un pincel de pelos; fórmula tibial 0-2-4. Abdomen concoloro a las alas, aproximadamente con 33 cerdas en el lado ventral del tercer segmento del macho.

Genitalia del macho (Figs. 19a-c). Gnathos en forma de "V"; proceso del anellus ahusado, cubierto de microespinas.

Genitalia de la hembra (Figs. 19d). Corpus bursae largo, delgado y membranoso; signum ausente.

Diagnosis y monofilia. Este género se distingue fácilmente de los demás por poseer antenas simples en ambos sexos, y que en el macho el proceso del anellus es ahusado cubierto de microespinas (autapomorfía del género). En la hembra por tener un corpus bursae largo, delgado, membranoso y asimétrico.
Distribución. Probablemente Corral sea la localidad tipo. Aunque no está citada en la etiqueta del ejemplar tipo si aparece en la descripción de Butler (1882). Género endémico de Chile, su registro más septentrional es Curacautín ( $38^{\circ} 30^{\circ}$ S) y el más austral Quellón, Chiloé (4330 `S). Su distribución se asocia al bosque templado del sur de Chile.

Observaciones. Rindge (1986) incluye en el género Odontothera dos especies de géneros totalmente distintos (ver observaciones al respecto en el género Proteopharmacis). $\mathrm{Su}$ identificación de la especie tipo de Odontothera es errada porque nunca examina el tipo descrito por Butler (1882). Por este error, crea un nuevo género Yalpa.

Pitkin (2002) incluye en la sinonimia también a Calta y Proteopharmacis; sin embargo, el análisis morfológico y filogenético de las especies de estos géneros en el presente trabajo, permiten removerlos de la sinonimia y reconocerlos como géneros válidos.

\section{Proteopharmacis Warren, 1895}

Proteopharmacis Warren 1895:153.

Proteopharmacis Warren. Fletcher 1979:172; Orfila y Schajovskoy 1959 (1960):17.

Especie tipo: Scotopteryx valdiviata Felder y Rogenhofer 1875. Reise öst. Fregatte Novara (Zool.) 2 (Abt. 2): pl. 126, fig. 6, para Proteopharmacis; designada por Warren 1895, p. 153.

Descripción. La apariencia general de las polillas es mostrada en las figuras 4a-h. Polillas de tamaño mediano, la longitud del ala anterior varía entre 13 y $18 \mathrm{~mm}$.

Antena simple en ambos sexos. Superficie dorsal de las alas anteriores en varias tonalidades del castaño, verdosas, grises o con una área media castaño oscura o clara; bandas antemedial y postmedial siempre representadas; en algunos ejemplares la banda medial es muy conspicua y en otras inconspicua; mancha discal presente o ausente. Superficie ventral de color castaño o castaño grisáceo, el patrón de maculación se repite al de la superficie dorsal pero en forma más débil. Alas posteriores: superficie dorsal variable en color, castaño clara u oscura, banda extradiscal presente o ausente; mancha discal presente o ausente. Superficie ventral con el mismo patrón de maculación que la región dorsal, pero las manchas débilmente marcadas. Venación de las alas anteriores: Sc paralela a $\mathrm{R}_{1}$, poco antes del término de la celda discal pueden llegar a juntarse para luego separarse; sin celda accesoria. Venación de las alas posteriores: $\mathrm{Sc}+\mathrm{Rs}$ unidas desde cerca de la base hasta un $1 / 3$ antes del término de la celda discal. Patas: tibias posteriores del macho con un pincel de pelos; fórmula tibial 0-2-4. Abdomen, machos con una fila de cerdas en la región ventral del tercer segmento abdominal; concoloro con las alas.

Genitalia del macho (Figs. 20a-c). Gnathos en forma de "V"; anellus reducido; proceso del anellus largo y delgado, glabro; vesica armada por espinas cónicas dispuestas en una hilera.

Genitalia de la hembra (Figs. 20d). Corpus bursae esférico, esclerosado y curvado hacia el lado izquierdo.

Diagnosis y monofilia. Este género se distingue fácilmente 


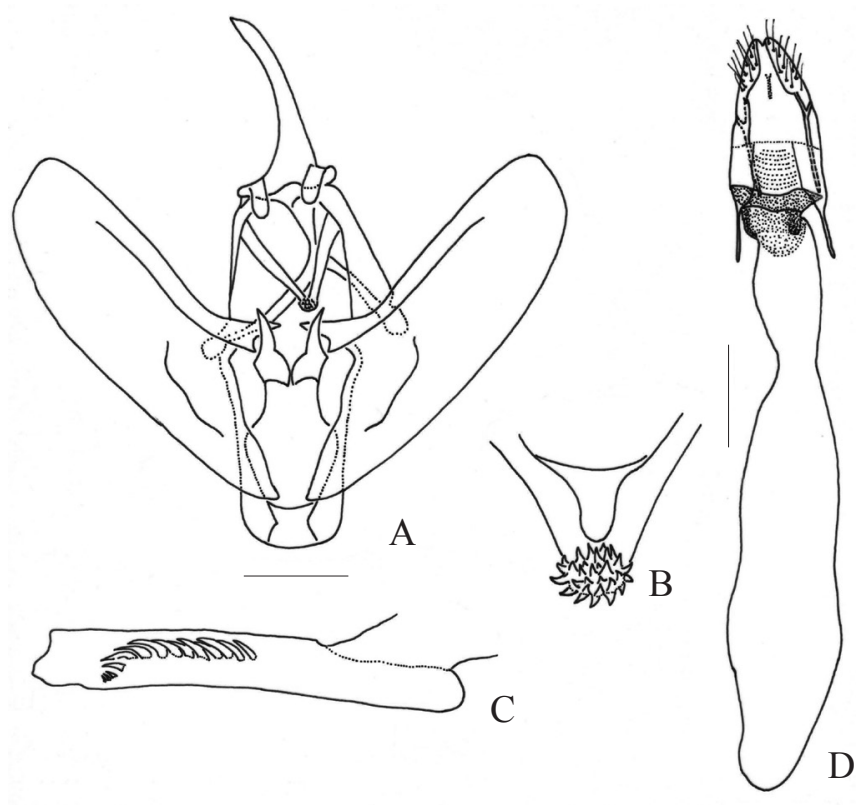

Fig. 19. Armaduras genitales del macho y hembra de Odontothera virescens. a) genitalia del macho en vista ventral; b) extremo del gnathos; c) aedeagus en vista lateral; y d) genitalia de la hembra en vista ventral. Escalas $0,25 \mathrm{~mm}$, figura $\mathrm{d} 1 \mathrm{~mm}$.

de todos los otros en la armadura genital de ambos sexos. En la genitalia el proceso del anellus es largo y delgado, acintado (autapomorfía); anellus tiene forma de correa, es reducido; vesica con espinas que están dispuestas de mayor a menor en una hilera y su número oscila entre las 16 y 20 espinas. Genitalia de la hembra con dos autapomorfias: corpus bursae esclerosado, estriado en su porción anterior y curvado hacia el lado derecho.

Distribución. Género endémico de la zona bajo estudio, su registro más septentrional es Limache (aproximadamente $33^{\circ}$ S) y el más austral Termas de Río Blanco, Cautín ( $\left.39^{\circ} \mathrm{S}\right)$, en Argentina hay registros en Pucará y San Martín de los Andes (Neuquén). Distribución asociada al bosque esclerófilo, templado y templado frío de Nothofagus.

Observaciones. Rindge (1986) coloca el género Proteopharmacis Warren en sinonimia con Odontothera. Para esto sólo se basa en la identificación de Odontothera virescens sobre ejemplares de la colección Sperry que habían sido determinados previamente por el Dr. Fletcher. Al revisar los tipos de las especies comprometidas en estos dos géneros, se concluye que Proteopharmacis es un género válido y que Odontothera, de acuerdo a las estructuras revisadas en el material tipo, es totalmente diferente y distinguible del género analizado en este apartado (ver observaciones para el género Odontothera).

La única especie del género es altamente variable en su patrón de maculación. Este hecho llevó a Butler (1882) a describir varias especies y variedades sobre ejemplares de ella. Cuando se revisa la armadura genital tanto del macho como de la hembra, de estas especies y variedades, no se encuentran diferencias entre los distintos ejemplares de cada una de ellas ni con el tipo.

Este patrón de maculación tan variable es el segundo caso que se registra para Chile, anteriormente se tiene constancia en un género de Noctuidae (Jana-Sáenz 1989) de la zona Patagónica y probablemente esté asociado a la amplia distribución de la especie (variación intrapoblacional del tipo ecológica).

\section{Psilaspilates Butler, 1893}

Psilaspilates Butler 1893: 458.

Psilaspilates Butler. Fletcher 1979:176; Rindge 1986:26; Parra, 1999a: 461.

Especie tipo: Panagra cavifasciata Butler 1882:384, para Psilaspilates Butler; designada por Fletcher 1979:176.

El género, el cual incluye ocho especies, fue revisado por Parra (1999a), por ello la información presentada aquí es restringida.

Diagnosis y monofilia. Alas anteriores variegadas de castaño oscuro y claro o amarillentas (Fig. 3g), el patrón de bandas de las alas en las especies del género son muy homogéneas, siendo el color amarillo y ocre lo más común.

Este género se distingue de los otros componentes de la tribu, por la combinación de una serie de caracteres de la armadura genital. Genitalia del macho, gnathos en forma de "V" (21 a y c); proceso del anellus en forma de huso, glabro (21d); aedeagus con un conjunto de espinas pequeñas y grandes agrupadas y escalonadas, la que constituye la autapomorfía del género (21b). Genitalia de la hembra, corpus bursae elongado, porción anterior membranosa, porción posterior esclerosada o membranosa pero con estrías siempre presente; signum pequeño, estrellado (21e).

Distribución. Género endémico de la zona en estudio, su registro más septentrional es Valparaíso $\left(33^{\circ} \mathrm{S}\right)$ y el más austral Tierra del Fuego $\left(55^{\circ} \mathrm{S}\right)$. $P$. catillata es la de distribución más amplia, $P$. ceres y $P$. signistriata tienen los registros más septentrionales y $P$. catillata y $P$. signistriata los más australes.

Observaciones. Más comentarios sobre el género en el trabajo de Parra (1999a).

Lista sistemática y sinonímica de los Lithinini de Chile y región Argentina adyacente (entre paréntesis géneros en los cuales las especies fueron originalmente descritas).

Acauro Rindge, 1986

rotundus Rindge, 1986

Asestra Warren, 1895

Siopla Rindge, 1986

bella Butler, 1882 (Pseudosestra)

derance Rindge, 1986 (Siopla)

Calta Rindge, 1986 stat. rev.

debilis (Butler, 1882) comb. nov. (Odontothera)

lamella Rindge, 1986 (Calta)

Euclidiodes Warren, 1895

Aspilaria Staudinger, 1898 (1899)

Catriela Orfila y Schajovskoy, 1959 (1960) 


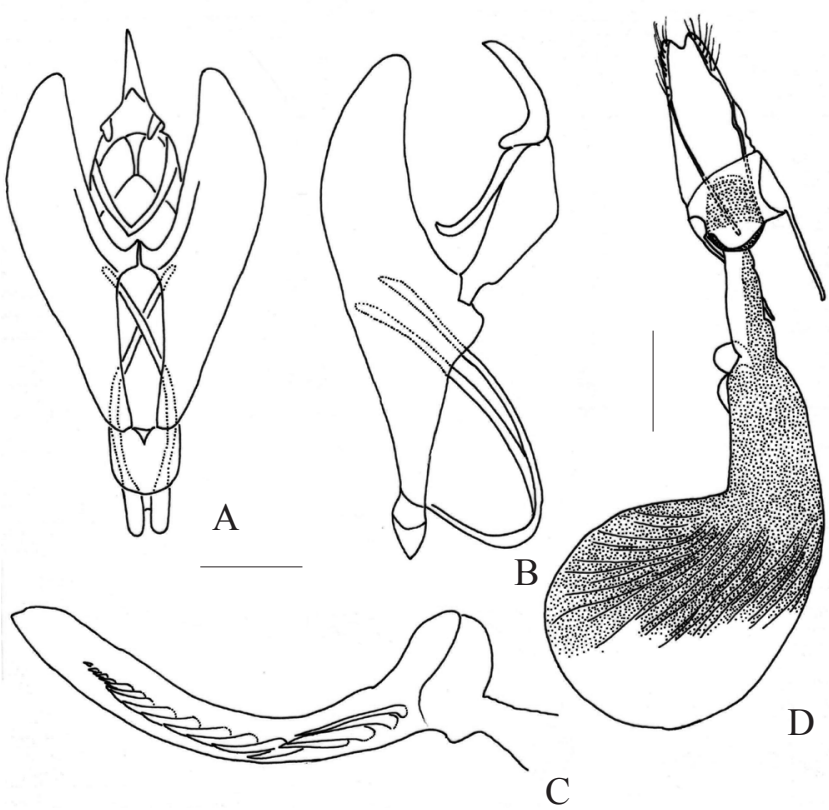

Fig. 20. Armaduras genitales del macho y hembra de Proteopharmacis valdiviata. a y b) genitalia del macho en vista ventral y lateral; c) aedeagus en vista lateral; y d) genitalia de la hembra en vista ventral. Escalas 0,25 mm, figura d $1 \mathrm{~mm}$.

Duraglia Rindge, 1986

Yapoma Rindge, 1986

agitata (Butler, 1882) (Heterophleps)

beechei Parra, 1999b

chiloensis (Butler, 1883) (Ypsipetes)

chone Rindge, 1986 (Yapoma)

meridionalis (Wallengren, 1860) (Eubolia)

bistrigata Bastelberger, 1907 (Psilaspilates)

citrinarius Mabille, 1885 (Aspilates)

ophiusina (Butler, 1882) (Heterophleps)

xanthe Rindge, 1986 (Duraglia)

Franciscoia Orfila y Schajovskoy, 1963

morenoi Orfila y Schajovskoy, 1963

ediliae Parra sp. nov.

Incalvertia Rindge, 1986 stat. rev.

Calvertia Warren, 1908 nec Calvertia Bourginat, 1880

valdiviana (Bartlett-Calvert, 1893) comb. nov. (Boarmia)

fumipennis Warren, 1908 (Calvertia)

catophoenissoides Angulo, 1977 (Talca)

Lacaria Orfila y Schajovskoy, 1959

aczeli Orfila y Schajovskoy, 1959

araucanaria Orfila y Schajovskoy, 1959

schajovskoyi Sperry, 1954 partim (Casbia)

orfilai Rindge, 1986

schajovskoyi Sperry, 1954 partim (Casbia)

picuncharia Orfila y Schajovskoy, 1959

phasma Butler, 1882

schajovskoyi (Sperry, 1954) (Casbia) monrosi Orfila y Schajovskoy, 1959 (Lacaria)

sperryi Orfila y Schajovskoy, 1954

Laneco Rindge, 1986

suffuscus Rindge, 1986

Maeandrogonaria Butler, 1893

Huechulafquenia Orfila y Schajovskoy, 1964

valentina Butler, 1893

formosa Orfila y Schajovskoy, 1964 sin. nov.

(Huechulafquenia)

Martindoelloia Orfila y Schajovskoy, 1963

juradoi Orfila y Schajovskoy, 1963

Nucara Rindge, 1986

recurva Rindge, 1986

Odontothera Butler, 1882 stat. rev.

Yalpa Rindge, 1986

virescens Butler, 1882

dalcahue Rindge, 1986 (Yalpa)

Proteopharmacis Warren, 1895 stat. rev.

valdiviata (Felder y Rogenhofer, 1875) (Scotopteryx)

ardescens Butler, 1882 sin. nov. (Pharmacis)

clara Butler, 1882 (Pharmacis)

insignis Butler, 1882 sin. nov. (Pharmacis)

latifasciata Butler, 1882 sin. nov. (Pharmacis)

latifasciata var. definita Butler, 1882 sin. nov. (Pharmacis)

mixta Butler, 1882 sin. nov. (Pharmacis)

mixta var. columba Butler, 1882 sin. nov. (Pharmacis)

mixta var. melanosticta Butler, 1882 sin. nov. (Pharmacis)

mixta var. seriata Butler, 1882 sin. nov. (Pharmacis)

trinotata Butler, 1882 (Pharmacis)

trinotata var. subocellata Butler, 1882 sin. nov.

(Pharmacis)

trinotata var. horrens Butler, 1882 sin. nov. (Pharmacis)

valdiviata var. albostriata Butler, 1882 sin. nov.

(Pharmacis)

Psilaspilates Butler, 1893

catillata (Felder y Rogenhofer, 1875) (Phasiane)

cavifasciata Butler, 1893 (Panagra)

saturata Staudinger, 1898 (1899) (Aspilaria)

cautinaria Parra, 1999a

ceres (Butler, 1882) (Lozogramma)

concepcionensis Parra, 1999a

obscura Parra, 1999a

signistriata (Butler, 1882) (Panagra)

arcuata Staudinger, 1898 (1899) (Aspilaria)

catilla Bastelberger, 1907

stygiana (Butler, 1882) (Heterophleps)

stygiana var. aurea Butler, 1882 (Heteropleps)

venata (Butler, 1882) (Liodes)

Rhinoligia Warren, 1895

biocellata (Felder y Rogenhofer, 1875) 


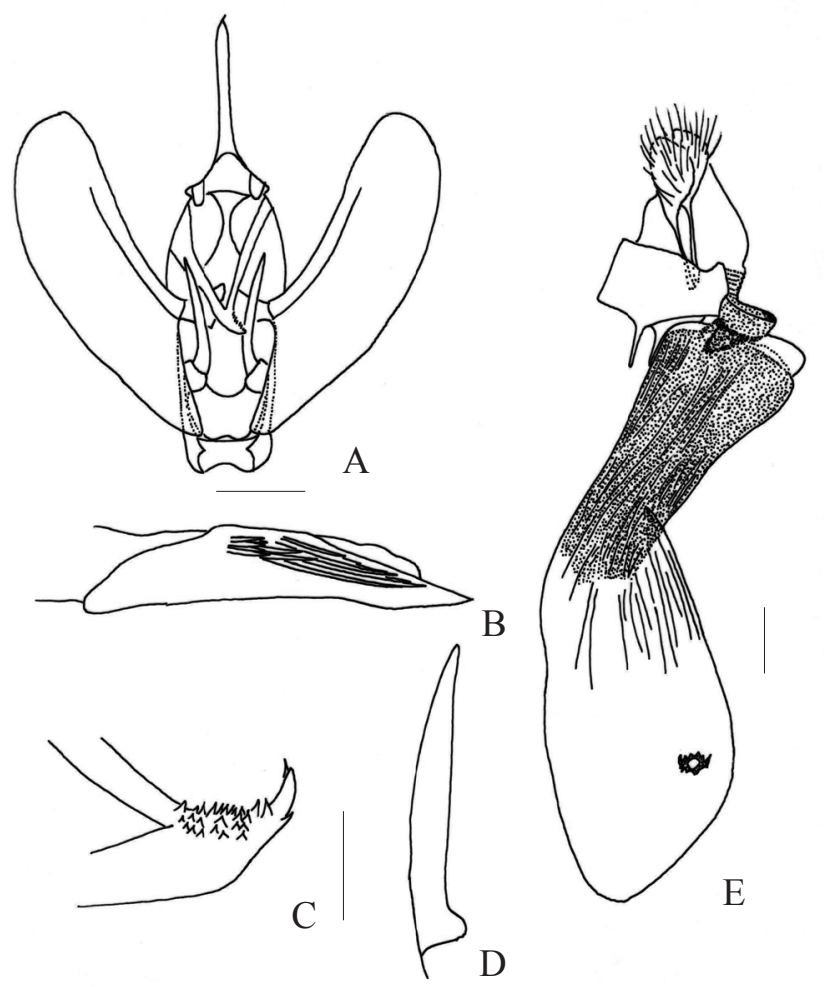

Fig. 21. Armaduras genitales del macho y hembra de Psilaspilates signistriata. a) genitalia del macho en vista ventral; b) aedeagus en vista lateral; c) extremo del gnathos; d) proceso del anellus; y e) genitalia de la hembra en vista ventral. Escalas $0,25 \mathrm{~mm}$, figura e $0,5 \mathrm{~mm}$.

Tanagridia Butler, 1882

Callemo Rindge, 1986

Guara Rindge, 1986

fusca Butler, 1882

monotonos Rindge, 1986

rhaphis Rindge, 1986

\section{DISCUSIÓN}

Filogenia de los Lithinini de Sudamérica austral

La hipótesis filogenética aquí generada muestra que los géneros Sudamericanos australes de Lithinini conforman un grupo monofilético; sin embargo, la monofilia de todos los géneros no está del todo clara y muchos sólo pueden ser caracterizados por un conjunto de caracteres plesiomórficos. Los valores de homoplasia son altos, esto se traduce en que no hay procesos dicotómicos claros entre los distintos géneros de la tribu lo cual indica que procesos reticulados podrían ser una mejor explicación de su diversificación (Fig. 22). El análisis de inferencia bayesiana muestra bajos valores de probabilidad a posteriori para los nodos, excepto en el nodo conformado por Rhinoligia + Incalvertia que si habrían diversificado de manera dicotómica (Fig. 1B). Sin embargo, el procesos de diversificación basado en una red de consenso de la aproximación bayesiana (Fig. 22), muestra que estos dos géneros hermanos formarían parte de un grupo con diversificación reticulada que comparten con Acauro,
Lacaria, Asestra, Nucara, Psilaspilates y Euclidiodes. Los restantes géneros forman parte de otro gran grupo con diversificación reticulada, el cual esta más cercano a la base del árbol o al origen de los Lithinini en Sudamérica (Fig. 1B y 22). En general el intento por establecer las sinapomorfías que definan los taxones hermanos resulta difícil utilzando caracteres morfológicos. Sólo un análisis más detallado de otros caracteres - como datos de inmaduros (v. gr. larvas, pupas y huevos) y DNA- permitirán una mejor resolución de la filogenia del grupo. Más aun de los geométridos asociados a los bosques templados del sur de Sudamérica que en forma global muestra muchos géneros monotípicos (Rindge 1983). Seguramente esta condición, sea un reflejo de la presencia de taxa relictuales que han conservado gran parte de los caracteres originales (Davis 1986) y que han seguido una especialización particular e independiente del resto de los Lithinini sudamericanos, condición que se ve favorecida por el aislamiento prolongado de los bosques australes, lo que ha repercutido también en la alta frecuencia de familias y géneros monotípicos de plantas (Villagrán \& Hinojosa 1997).

Nuestros resultados apoyan la propuesta original de Rindge (1986), quien a pesar de no sustentar la monofilia de los Lithinini a nivel mundial, afirma que el grupo es homogéneo y que al menos el análisis de los huevos (Salkeld 1983) así lo demuestra. Holloway (1993 (1994)) concuerda con esta idea y plantea que probablemente la presencia de 6 cerdas en la cara externa del espuripedio de las larvas sea el carácter que pruebe la monofilia del grupo. Sin embargo, esta idea no esta exenta de discusión dado que McGuffin (1987) afirmo que las larvas analizadas para la región Neártica presenten entre 5 y 6 cerdas sobre esta estructura.

Taxonomía. Rindge (1986) señala la presencia de 19 géneros y 37 especies de Lithinini para Chile y Argentina, mientras que Parra (1997) reconoce la presencia de 21 géneros y 38 especies de esta tribu en los bosques templados del sur de Chile y Argentina. Posteriormente Pitkin (2002), en su análisis de los Ennominae de Sudamérica, señala que los Lithinini están compuestos por 12 géneros y 38 especies. Inicialmente Rindge (1986) incluyó en este grupo al género Catophoenissa; sin embargo, el análisis morfológico de las especies manifiestan su clara posición en la tribu Nacophorini, principalemente porque las antenas tienen una rama espatulada y, en la genitalia del macho, una juxta grande y el proceso anellar no setoso (Parra 1997 y Pitkin 2002). Pitkin (2002) señala que la forma estrecha del proceso del anellus en Catophoenissa es bastante inusual en los Nacophorini y que este carácter indicaría una relación cercana de este género con los Lithinini. En la nueva proposición de Pitkin, basada en un análisis morfológico tradicional, aparentemente se conforman géneros que no manifiestan la descendencia de un ancestro común. La hipótesis de parentesco entregada en nuestro trabajo nos permite revalidar géneros que fueron tratados como sinónimos en el trabajo de Pitkin (2002), y al mismo tiempo validar e incorporar las nuevas entidades propuestas en ese estudio. Nuestras principales conclusiones respecto de lo anterior son: 1) Yalpa Rindge, es tratado como sinónimo junior de Odontothera. 2) El género Rhinoligia Warren es incorporado a los Lithinini. 3) El género Siopla Rindge es sinónimo junior de Asestra, Yapoma Rindge y 


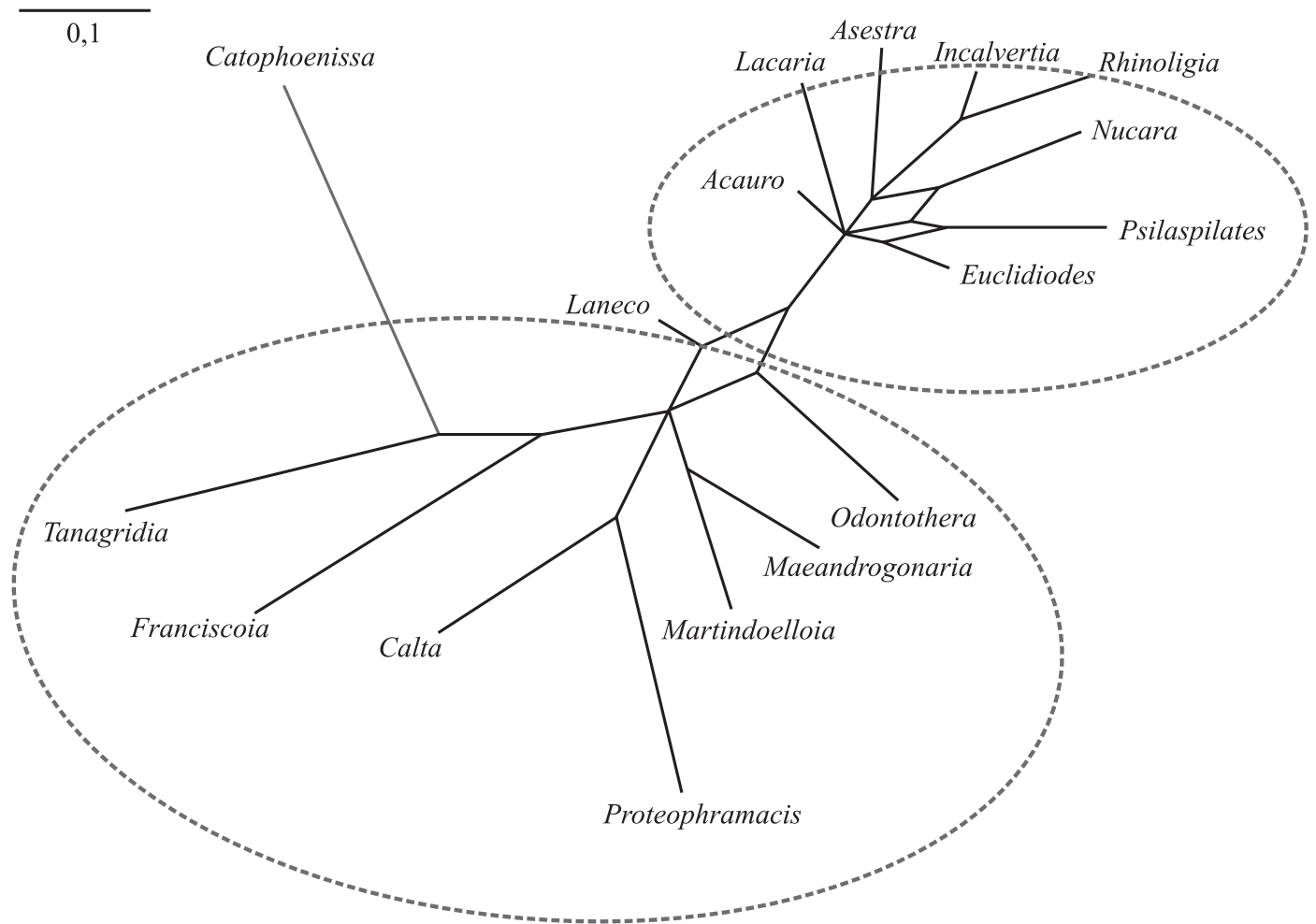

Fig. 22. Red de consenso de los 80.383 árboles de la aproximación Bayesiana a un umbral de $\mathrm{p}=0.25$ para los géneros de Lithinini. Esta red de consenso se considera útil en casos en los cuales la evolución ocurre de manera reticulada, y fue construida en base a la propuesta de Holland \& Moulton (2003) y Holland et al. (2004), en el programa SplitsTree 4 (Huson \& Bryant 2006).

Duraglia Rindge son sinónimos de Euclidiodes Warren, mientras que Callemo Rindge y Guara Rindge son sinónimos de Tanagridia, lo que es coincidente con la proposición de Pitkin (2002). 4) Los géneros Calta Rindge, Incalvertia Rindge, Odontothera Butler y Proteopharmacis Warren, sinonimizados por Pitkin, son redefinidos, revalidados e incorporados a la tribu Lithinini.

Distribución de los Lithinini. La tribu Lithinini está ampliamente repartida por el mundo, se encuentra en todas las regiones faunísticas conocidas. Para América del Sur, sólo existe la revisión moderna de Rindge (1986) referida a la fauna de Chile y Argentina. Las 36 especies de Lithinini consideradas en el presente estudio muestran una distribución restringida al sur de Chile y al sudoeste de Argentina, entre $\operatorname{los} 33^{\circ}$ y los $55^{\circ}$ de latitud Sur. Las especies con registros más septentrionales corresponden entre otras a $P$. valdiviata, $E$. agitata, E. beechei, $N$. recurva, $P$. ceres en la zona de Valparaíso; y las más australes E. meridionalis y $P$. catillata, en las islas del Canal Beagle y Tierra del Fuego.

De los resultados expuestos en este trabajo se deduce que podemos distinguir dos centros de distribución, que se asocian a las provincias biogeográficas propuestas por Irwin \& Schlinger (1986). El primero se sitúa en las regiones caracterizadas por un clima frío y húmedo, con bosques templados dominados por Nothofagus y vegetación asociada. Estas zonas corresponden a las provincias bióticas: Bosque Valdiviano, Bosque Valdiviano del Norte, Pehuenar y Cordillera de Valdivia, esta última en el lado argentino. El otro centro de distribución se sitúa en las provincias Desierto de Coquimbo (en su parte central y sur) y Valle Central. El clima es seco a relativamente seco, con una precipitación anual de $350 \mathrm{~mm}$ en el extremo norte y de $1500 \mathrm{~mm}$ en la zona sur. En esta zona se encuentran las formaciones arbóreas dominantes son respectivamente la estepa de Acacia caven (Mimosaceae) y el bosque de Nothofagus glauca. En muchos lugares estos tipos de vegetación se mezclan con los elementos del bosque templado, especialmente entre los ríos Maule y Biobío (Armesto et al. 1996). Esta condición explica la distribución de varias especies en ambientes diferentes en cuanto a condiciones ambientales.

Al poseer un clima más húmedo y una mayor área de bosques templados (Veblen et al. 1996), en Chile las especies de Lithinini asociadas a ellos, están más ampliamente distribuidas que en Argentina. Así, sólo se conocen especies de esta tribu en la zona andina de Neuquén, Argentina (Cordillera de Valdivia), en donde este tipo de bosque también está presente (Bosque templado frío de Nothofagus). De hecho, las especies Acauro rotundus, Euclidiodes xanthe, E.beechei, E. chiloensis, E. derance, Tanagridia rhaphis, Incalvertia valdiviana, Franciscoia ediliae, Laneco suffuscus, Nucara recurva, Odontothera virescens, Proteopharmacis valdiviata, Psilaspilates cautinaria, P. concepcionensis, $P$. obscura y Rhinoligia biocellata son conocidas sólo de Chile. Por el contrario, Lacaria araucanaria, L. aczeli y L. sperryi se encuentran en Argentina solamente.

La mayoría de las especies citadas en el lado argentino y chileno tienen su centro de distribución en los bosques templados y húmedos, en cambio las especies mayoritariamente distribuidas en las provincias Desierto 
de Coquimbo y Valle Central, sólo se encuentran en territorio chileno (v. gr. A. rotundus, E. derance entre otras). Probablemente la ausencia en el lado argentino de algunas especies ampliamente distribuidas en el Bosque Valdiviano se deba solamente a la falta de un exhaustivo muestreo en dicha zona.

Historia natural de los Lithinini. Prácticamente nada se sabe de la biología de estas polillas en la región donde se ha llevado a cabo este estudio; toda la información se refiere a la taxonomía de las especies. Los datos que existen se refieren a especies del Hemisferio Norte (McGuffin 1987). De acuerdo con este autor, los huevos tienen un corto período de incubación, la larva se alimenta de helechos, coníferas o angiospermas, la pupación ocurre en el suelo en una celda y constituye el período invernante. Allí presentan una sola generación al año. Sin embargo, los registros de recolección para la zona en estudio muestran que los adultos son activos 11 meses del año. Conviene puntualizar la falta de estudios faunísticos sobre el grupo. Cuando esta carencia sea subsanada, sin duda se obtendrán períodos más amplios en bastantes especies. Por ejemplo, los adultos de Lacaria picuncharia y Euclidiodes agitata poseen el período más largo de vuelo (hasta 7 meses). Mientras otras un período muy corto, tales como $F$. ediliae con alrededor de un mes. Es posible que en las especies exista más de una generación o que éstas estén representadas en otros meses, no obstante esto sólo se podría afirmar con un muestreo adecuado.

Algunos adultos tienen un período de vuelo temprano entre los meses de julio y enero (invierno - verano). Esto sugiere que disponen de un período muy extenso de desarrollo larvario (verano y principios de otoño) con alimento abundante y fácilmente accesible. La pupa sufriría una diapausa durante el otoño-invierno para emerger a mediados del invierno. En otros casos existe un período de vuelo tardío, entre noviembre y abril-mayo (finales de primavera a finales de otoño). En este caso, y dependiendo de las especies, lo más probable es que sean los huevos, o quizás larvas jóvenes, los que sufran una diapausa invernal.

Obviamente gran parte del conocimiento de la historia natural de los Lithinini de Sudamérica aún está en desarrollo. Sin embargo, nuestro estudio filogenético morfológico basado en aproximación de máxima parsimonia y probabilidades (BMCMC), constituye la base sistemática necesaria sobre la cual otros estudios (e.g. Biogeográficos, Ecológicos, Fisiológicos, Evolutivos, etc.) pueden comenzar a realizarse.

Agradecimientos. El primer autor agradece al Dr. Ariel Cammouseight y Mario Elgueta (MNHN), Dra. Viviane Jerez R. (MZUC) Chile y, Dr. Fernando Navarro y Dra. Adriana Chalup (IML) Argentina, por la valiosa cooperación en la obtención de los ejemplares tipos y literatura relacionada con este estudio. Del mismo modo agradece al Dr. Malcolm J. Scoble (BMNH) por las facilidades otorgadas durante su visita al The Natural History Museum y, el estudio de los tipos depositados en aquella institución. Y finalmente a los Drs. Francisco Ocharan y Nuria Anadón de la Universidad de Oviedo, por sus comentarios y consejos durante la estadía y desarrollo de la tesis doctoral en Oviedo, España; y a los evaluadores que ayudaron a mejorar este manuscrito. Este trabajo contó con el apoyo financiero del Proyecto 98.113.047-1.D.1 y el Proyecto de Instrumental Científico 2001 de la Dirección de Investigación de la Universidad de Concepción.

\section{REFERENCIAS}

Angulo, A. O. 1977. Talca catophoenissoides sp. nov.; nueva especie de Nacophorini de Chile (Lepidoptera: Geometridae). Boletín de la Sociedad de Biología de Concepción, Chile 51: 305-310.

Angulo, A. O. \& M. E. Casanueva. 1981. Catálogo de los lepidópteros geométridos de Chile (Lepidoptera: Geometridae). Boletín de la Sociedad de Biología de Concepción, Chile 51: 7-39.

Armesto, J. J.; P. León \& M. K. Arroyo. 1996. Los bosques templados del sur de Chile y Argentina: una isla biogeográfica. p. 23-28. In: Armesto, J. J.; C. Villagrán \& M. K. Arroyo (eds.) Ecología de los bosques nativos de Chile. Editorial Universitaria, Santiago 470 p.

Bastelberger, W. 1907. Neue exotische Geometriden. Berliner Entomologische Zeitscrhrift 52: 53-62.

Bartlett-Calvert, W. 1893. Nuevos lepidópteros de Chile. Anales de la Universidad de Chile 84: 813-834.

Bourguinat, J. R. 1880. Etudes sur les fossils tertiaires et quarternaires de la vallée de la Cettna en Dalmatie. Imprimerie D. Bardin, SaintGermain, 55 p.

Bremer, K. 1994. Branch support and tree stability. Cladistics 10: 295-304.

Butler, A. G. 1882. Heterocerous Lepidoptera collected in Chili by Thomas Edmonds. Esq. Part III.-Geometrites. Transactions of the Entomological Society of London 3: 339-423.

Butler, A. G. 1883. Heterocerous Lepidoptera collected in Chili by Thomas Edmonds, Esq. Part IV Pyrales and Micros. Transactions of the Entomological Society of London 49-90.

Butler, A. G. 1893. On a small collection of Lepidoptera from Chili. The Annals and Magazine of Natural History, ser. 6, 12: 457-467.

Craw, R. 1989. New Zealand biogeography: a panbiogeographic approach. New Zealand Journal of Zoology 16: 527-547.

Crisci, J. V.; M. M. Cigliano; J. J. Morrone \& S. Roig-Juñent. 1991a. A comparative review of cladistic approaches to historical biogeography of southern South America. Australian Systematic Botany 4: 117-126.

Crisci, J. V.; M. M. Cigliano; J. J. Morrone \& S. Roig-Juñent. $1991 \mathrm{~b}$. Historical Biogeography of Southern South America. Systematic Zoology 40: 152-171.

Davis, D. R. 1986. A new Family of Monotrysian from Austral South America (Lepidoptera: Palaephatidae), with a Phylogenetic Review of the Monotrysia. Smithsonian Contributions to Zoology 434: 1-202.

Dugdale, J. S. 1989. New Zealand Lepidoptera: basic biogeography. New Zealand Journal of Zoology 16: 679-687.

Felder, C. \& A. F. Rogenhofer. 1875. Reise de österrreichischen Fregatte Novara um die Erde (Zoologischer Theil) Band 2(Abtheilung 2): pls 121-140. Wien.

Felsenstein, J. 1985. Condence limits on phylogenies: An approach using the bootstrap. Evolution 39: 783-791.

Fletcher, D. S. 1979. Geometroidea. In: Nye, I. W. B. (ed.) The Generic Names of moth of the World. London. Trustees of the British Museum (Natural History), $3 \mathrm{xx}+243 \mathrm{p}$.

Forbes, W. T. M. 1948. Lepidoptera of New York and neighboring states. Part II. Memoir Cornell University Agricultural Experimental Station 274: $1-263$.

Gaston, K. J.; M. J. Scoble \& A. Cook. 1995. Patterns in species descriptions: a case study using the Geometridae (Lepidoptera). Biological Journal Linnean Society 55: 225-237.

Heppner, J. B. 1991. Faunal Regions and the diversity of Lepidoptera. Tropical Lepidoptera 2: 1-85.

Holland B. \& Moulton V. 2003. Consensus networks: A method for visualizing incompatibilities in collections of trees. p. 165-176. In: G. Benson \& R. Page (ed.) Proceedings of "Workshop on Algorithms in Bioinformatics", volume 2812 of LNBI, Springer.

Holland, B. R.; K. T. Huber; V. Moulton \& P. J. Lockhart. 2004. Using consensus networks to visualize contradictory evidence for species phylogeny. Molecular Biology and Evolution 21: 1459-1461.

Holloway, J. D. 1993 (1994). The Moths of Borneo: Family Geometridae, Subfamily Ennominae; Part 11. Malayan Nature Journal 47: 1-309.

Huson, D. H. \& D. Bryant. 2006. Application of Phylogenetic Networks in Evolutionary Studies. Molecular Biology and Evolution 23: 254-267.

Huelsenbeck, J. P. \& J. P. Bollback. 2001. Empirical and hierarchical Bayesian estimation of ancestral states. Systematic Biology 50: 351366. 
Irwin, M. E. \& E. I. Schlinger. 1986. A gazetteer for the 1966-67 University of California - Universidad de Chile. Arthropod expedition to Chile and parts of Argentina. Occasional Papers of the California Academy of Science 144: 1-11.

Jana-Sáenz, C. 1989. Estudio crítico del género austral Caphornia Koehler, 1958 (Lepidoptera, Noctuidae). Gayana Zoología 53: 77-111.

Jerez, V. 1996. Biology and phylogenetic remarks of the sub-antarctic genera Hornius, Stenomela and Dictyneis (Chrysomelidae: Eumolpinae). p. 239-258. In: Jovilet, P. H. A. \& M. L. Cox (eds). Chrysomelidae Biology vol. 3: General studies. Amsterdam, SPB Academic Publishing, 365 p.

Lynch, J. D. 1990. Refugia. p. 311-342. In: Myers, A. A. \& P. S. Giller (Eds.) Analytical biogeography. And integrated approach the study of animal and plant distributions. London, Chapman and Hall, $578 \mathrm{p}$.

Mabille, M.P. 1885. Diagnoses de Lépidopteres nouveaux. Bulletin de la Societé Philomathique Paris 7: 55-70.

McGuffin, W. C. 1972. Guide to the Geometridae of Canada (Lepidoptera). II. Subfamily Ennominae. 1. Memoirs of the Entomological Society of Canada 86: $1-59$.

McGuffin, W. C. 1977. Guide to the Geometridae of Canada (Lepidoptera). II. Subfamily Ennominae. 2. Memoirs of the Entomological Society of Canada 101: 1-191.

McGuffin, W. C. 1982. Guide to the Geometridae of Canada (Lepidoptera). II. Subfamily Ennominae. 3. Memoirs of the Entomological Society of Canada 117: $1-153$.

McGuffin. W. C. 1987. Guide to the Geometridae of Canada (Lepidoptera). II. Subfamily Ennominae. 4. Memoirs of the Entomological Society of Canada 138: $1-182$.

Moore, D. 1983. The flora of the Fuego-Patagonian Cordilleras: Its origens and affinities. Revista Chilena de Historia Natural 56: 123-136.

Müller, K. 2004. PRAP - computation of Bremer support for large data sets. Molecular Phylogenetics and Evolution 31: 780-782.

Müller, K. 2005. The efficiency of different search strategies in estimating parsimony jackknife, bootstrap, and Bremer support. BMC Evolutionary Biology 5: 58 .

Munroe, E. 1982. Lepidoptera. p. 612-651 In: Parked, S. B. (ed.) Synopsis and classification of living organisms. McGraw-Hill.

Nielsen, E. S. 1985. Primitive (non-ditrysian) Lepidoptera of the Andes: diversity, distribution, biology and phylogenetic relationships. Journal Research Lepidopterology, Supplement 1: 1-16.

Nixon, K. C. 2002. WinClada ver. 1.00.08 Ithaca, Published by the author, NY.

Orfila, R. N. \& S. Schajovskoy. 1959. Geometridae (Lepidoptera) del Parque Nacional Lanín (Argentina). I. El género Lacaria nov. Acta Zoológica Lilloana 17: 197-216.

Orfila, R. N. \& S. Schajovskoy. 1959 (1960). Geometridae (Lep.) del Parque Nacional Lanín Argentina. II. El género Euclidiodes Olim (Ennominae). Revista de la Sociedad Entomológica Argentina 22: 7-33.

Orfila, R. N. \& S. Schajovskoy. 1963. Geometridae (Lep.) del Parque Nacional Lanín (Argentina). III. Géneras y especies nuevos de Ennominae. Physis 24: $1-10$

Orfila, R. N. \& S. Schajovskoy. 1964. Geometridae (Lepidoptera) del Parque Nacional Lanín (Argentina). IV. Dos géneros y especies nuevos de Ennominae. Acta Zoológica Lilloana 20: 21-32.

Pagel, M. \& A. Meade. 2004. A Phylogenetic Mixture Model for Detecting Pattern-Heterogeneity in Gene Sequence or Character-State Data. Systematic Biology 53: 571-581.

Parra, L. E. 1997. Revisión de los Lithinini y Trichopterygini (Lepidoptera: Geometridae) de Chile y de la Región Andina Argentina adyacente. Tesis doctoral, Universidad de Oviedo. 469 p.

Parra, L. E. 1999a. Revision of the Neotropical Genus Psilaspilates (Lepidoptera: Geometridae). Annals of the Entomological Society of America 92: 460-472.

Parra, L. E. 1999b. Revisión del género Euclidiodes Warren, 1894 (Lepidoptera: Geometridae). Revista Chilena de Historia Natural 72: 643-659.

Pitkin, L. M. 2002. Neotropical Ennominae moths: a review of the genera (Lepidoptera: Geometridae). Zoological Journal of the Linnean Society 135: 121-401.
Rindge, F. H. 1964. A revision of the genera Melanolophia, Pherotesia and Melanotesia (Lepidoptera, Geometridae). Bulletin of the American Museum of Natural History 126: 241-434.

Rindge, F. H. 1966. A revision of the moth genus Anacamptodes (Lepidoptera, Geometridae). Bulletin of the American Museum of Natural History 132: $230-350$

Rindge, F. H. 1967. A revision of the Neotropical species of the moth genus Glena (Lepidoptera, Geometridae). Bulletin of the American Museum of Natural History 135: 107-172.

Rindge, F. H. 1971. A revision of the Nacophorini from cool and cold temperate southern South America (Lepidoptera, Geometridae). Bulletin of the American Museum of Natural History 145: 303-392.

Rindge, F. H. 1973. Notes on and descriptions of South American Nacophorini (Lepidoptera, Geometridae). American Museum Novitates 2531: $1-42$.

Rindge, F. H. 1975. A revision of the new world Bistonini (Lepidoptera, Geometridae). Bulletin of the American Museum of Natural History 156: $69-156$.

Rindge, F. H. 1978. A revision of the genus Sabulodes (Lepidoptera, Geometridae). Bulletin of the American Museum of Natural History 160: 193-292.

Rindge, F. H. 1983. A generic revision of the new world Nacophorini (Lepidoptera, Geometridae). Bulletin of the American Museum of Natural History 175: 147-262.

Rindge, F. H. 1986. Generic descriptions of new world Lithinini (Lepidoptera, Geometridae). American Museum Novitates 2838: 1-68.

Salkeld, E. H. 1983. A catalogue of the eggs of some Canadian Geometridae (Lepidoptera), with comments. Memoirs of the Entomological Society of Canada 126: 1-271.

Scoble, M. J. 1995. The Lepidoptera. Form, Function and Diversity. London. The Natural Hisdtory Museum \& Oxford University Press, $404 \mathrm{p}$.

Scoble, M. J.; K. J. Gaston \& A. Crook. 1995. Using taxonomic data to estimate species richness in Geometridae. Journal of the Lepidopterists' Society 49: 136-147.

Simpson, G. 1971. Pleistocene changes in the fauna and flora of South America. Science 173: 771-779.

Sperry, J. A. 1954. Neotropical Geometridae apparently undescribed. Bulletin, Southern California Academy of Science 53: 69-74.

Staudinger, O. 1898 (1899). Lepidopteren. Hamburger Magalhaensischen Sammelreise 4: 1-117.

Swofford, D. L. 2002. PAUP* Beta Version. Phylogenetic Analysis Using Parsimony (*and other methods). Sunderland, Sinauer Associated.

Veblen, T. T.; T. Kitzberger; B. R. Burns \& A. J. Rebertus. 1996. Perturbaciones y dinámica de regeneración en bosques andinos del sur de Chile y Argentina. p. 169-198. In: Armesto, J. J.; C. Villagrán \& M. K. Arroyo (eds.) Ecología de los bosques nativos de Chile. Santiago Editorial Universitaria, $470 \mathrm{p}$.

Villagrán, C. \& J. Varela. 1990. Palynological Evidence for Increased Aridity on the Central Chilean Coast during the Holocene. Quaternary Research 34: 198-207.

Villagrán, C.; P. Moreno \& R. Villa. 1995. Antecedentes palinológicos acerca de la historia cuaternaria de los bosques chilenos. pp. 51-69. In: Armesto, J. J.; C. Villagrán \& M. K. Arroyo (eds.) Ecología de los bosques nativos de Chile. Santiago Editorial Universitaria, $470 \mathrm{p}$.

Villagrán, C. \& L. F. Hinojosa. 1997. Historia de los bosques del sur de Sudamérica, II: análisis fitogeográfico. Revista Chilena de Historia Natural 70: 225-239.

Wall, P. K.; J. Leebens-Mack; K. F. Müller; D. Field; N. S. Altman \& C. W. dePamphilis. 2008. PlantTribes: A gene and gene family resource for comparative genomics in plants. Nucleic Acids Research 36: 970-976.

Wallengren, H. D. J. 1860. Lepidopterologische Mittheilungen. Wiener Entomologische Monatschrift 4: 161-181.

Warren, W. 1895. New species and genera of Geometridae in the Tring Museum. Novitates Zoologicae 2: 82-159.

Warren, W. 1908. Descriptions of new species of South American Geometrid moths. Proceding US National Museum 34: 91-110. 


\section{ANEXO 1}

\section{EJEMPLARES EXAMINADOS Y LOCALIDADES CITADAS EN LA LITERATURA}

\section{Calta}

Calta debilis: CHILE: 1 macho, HOLOTIPO, Chili, 82107. ARGENTINA: 1 macho y 1 hembra, Pucará, Parque N. Lanín, II-1954, leg. Schajovskoi (BMNH).

Citas bibliográficas. CHILE: Valdivia (Butler, 1882); Valdivia, Osorno, Llanquihue, Chiloé (Rindge, 1986). ARGENTINA: Neuquén (Rindge, 1986).

\section{Catophoenissa}

Catophoenissa dibapha: CHILE: 1 macho, HOLOTIPO (E. dibapha), Chile (BMNH); 1 macho, HOLOTIPO ( $C$. dibapha albicentra), Pemehue, 800 m, 12-I-1946; 1 hembra, ALOTIPO (C. dibapha albicentra), Valdivia, II-1891 (MNHN). Villa Santa Julia, Camino Bulnes, Provincia de Concepción: 1 macho, 24-II-1971, 1 macho, 1 hembra, 1-III1971, 1 macho, 2-III-1971, 1 macho, 5-III-1971, 2 machos, 7-III-1971, 2 machos, 10-III-1971, 1 macho y 1 hembra, 20-III-1971, 6 machos, 1 hembra 24-III-1971, 1 macho, 27-III-1971, 2 machos, 17-I-1982 (MZUC). Concepción: 1 macho, 22-III-1959, 1 hembra, 2-II-1960, 1 macho, 27-II1960, 1 macho, 1-III-1960, 1 macho, 7-III-1960, 4 machos, 12-III-1960, 1 macho, 13-III-1960, 1 macho, 16-III-1960, 1 macho, 17-III-1960, 2 machos, 20-III-1960, 1 macho, 25-III1960, 1 macho, 29-IV-1960, 1 macho, 4-III-1961, 1 macho y 1 hembra, 6-III-1961, 2 machos, 8-III-1961, 1 macho, 10III-1961, 3 machos, 13-III-1961, 1 macho, 15-III-1961, 1 macho, 19-III-1962, 1 macho, 28-III-1962, 7 machos, 10-III1972, 1 macho, 15-III-1972, 1 macho, 10-XI-1975, 1 hembra, III-1980 (MZUC). Chillán:1 hembra, 28-I-1982, 1 hembra, 20-II-1960, 1 hembra, 27-II-1960, 1 macho, 10-III-1960, 1 macho, 12-III-1960, 1 hembra, 16-III-1960, 1 macho, 25-III1960, 1 hembra, 6-IV-1960 1 macho, 13-IV-1960, (MZUC). 1 macho, La Invernada, Ñuble, I-II-1970, L.E. Peña coll.; 1 macho, Fundo Sta. Elisa, la Unión, 8-II-1957, J. Salgado coll.; 1 macho, Puyehue, 21-I-1965; 1 macho, Maullín, 24-I-1944; 1 macho, Temuco, 25-II-1976, Trampa coll.; 1 macho, Cobquecura, 27II-1972, Ramírez coll.; 1 hembra, Maullín, XI-1943, S. Barros coll.; 1 hembra, La Serena, 20-II-1961 (MZUC). ARGENTINA: 1 macho, S.M. Andes, II-1950, 1. Schajovskoi (IML).

Citas bibliográficas. CHILE: Talcahuano, Pemehue, Caleta Tirúa (Cautín), Galvarino, Curacautín, Valdivia, Ancud (Ureta, 1956). Coquimbo, Valparaíso, Santiago, Maule, Talcahuano, Pemehue, Cautín, Valdivia, Osorno, Chiloé (Rindge, 1971). ARGENTINA: Rio Negro, Bariloche, San Carlos de Bariloche (Rindge, 1971).

Catophoenissa fuenzalidai: CHILE: 1 macho, HOLOTIPO, La Obra, Valle del Maipo, 19-III-1953; 1 hembra, ALOTIPO, Viña del Mar, 1-V-1954 (MNHN); 1 macho, Marga Marga, 9-IV-1955; 1 macho, Viña del mar,
1954; 5 machos, Guayacán, Santiago, III-1951; 2 machos, El Manzano, Santiago, 22-III-1951; 1 macho, Villa Sta. Julia, Concepción, km 25 cam. Bulnes, Trampa coll. (MZUC).

Citas bibliográficas. CHILE: Los Vilos; La Obra, El Arrayán, Guayacán, Las Condes (Santiago); Viña del Mar; El Cardenal (Colchagua); Diguillín (Ñuble) (Ureta, 1856). Coquimbo, Aconcagua, Valparaíso, Santiago, Colchagua, Curicó, Chillán (Rindge, 1971).

\section{Euclidiodes}

Euclidiodes agitata: CHILE: 1 macho, HOLOTIPO, Chili, 82-107; 1 hembra, ALOTIPO, Chili, 82-107 (BMNH); 1 hembra, Chile Central; 1 macho, Chili, Edmonds (MBNH); 1 macho, Quebrada Macul, 1-IV-1953; Viña del Mar: 2 machos, 21-III-1953, 1 hembra, 28-III-1953; La Obra, Santiago: 1 macho, 9-IV-1953, 3 hembras, 16-IV-1953; 1 macho y 1 hembra, Peñalolén, 14-V-1953; Guayacán, Santiago: 1 hembra, IV-1943, 1 hembra, V-1943 (MNHN); 4 machos y 5 hembras, Guayacán, Santiago, III-1951; 1 hembra, La Poza Azul, Quilpué, 17-IV-1952, G. Monsalve (MZUC). ARGENTINA: 1 macho, San Martín de Los Andes, Neuquén, 16-II-1952; 1 macho, San Martín de los Andes, Neuquén, N. Patagonia, II-1952, S. Schajovskoi; 4 machos y 3 hembras, Valley del Lago Blanco, Chubut (Thursby) (BMNH).

Citas bibliográficas. CHILE: Valparaíso (Butler, 1882). ARGENTINA: Pucará, San Martín de los Andes (Orfila y Schajovskoy, 1959 (1960)).

Euclidiodes beechei: CHILE: 1 macho, HOLOTIPO, Viña del Mar, 15 mayo 1953; 1 hembra, ALOTIPO, Peñalolén, 14 mayo 1953 (MNHN). PARATIPOS: 1 macho, Hualpén, 13 octubre 1992, L. Parra coll.; 1 macho, Talca, 16 octubre 1986, E. Arias col.; 1 hembra, Talca, 4 octubre 1986, E. Arias col. (MZUC).

Euclidiodes chiloensis: CHILE: 1 macho, HOLOTIPO, Chili, 82-107; 1 macho, Mittel Chile, Cauquenes, Schönemann; 1 macho, Chili, Valdivia, Artur V. Lossberg (BMNH).

Citas bibliográficas. CHILE: Chiloé (Butler, 1882).

Euclidiodes meridionalis: CHILE: 1 macho, Chili, 1 macho, Patagonia, 1 macho, Magellan, 93-162, 1 macho Patagonia, 84-72 (BMNH); 1 macho, Dalcahue, Isla Chiloé (E), 10-12-II-1954, coll. L.E. Peña; 2 machos, Pto. Natales, II-1953, Alarcón coll.; 1 hembra, Pucón, Valdivia, XI-1950, n.n. coll.; 1 macho y 1 hembra, Aysén, 10-I-1996, Trampa Luz coll. (MZUC).

Citas bibliográficas. CHILE: Bahía Orange (Cabo de Hornos) (Mabille, 1885). ARGENTINA: Río Grande, Ushuaia (Staudinger, 1898 (1899)).

Euclidiodes ophiusina: CHILE: 1 macho, HOLOTIPO, Chili, 82-107, 1 hembra, ALOTIPO, Chili, 82-107; 1 macho, Castro, 20-22-XI-1926, Chiloé I., F. \& M. Edwards (BMNH); Concepción: 1 macho, 5-XI-1959, 1 macho, 5-XI-1960, 
Trampas U.V. coll. (MZUC). ARGENTINA: 2 hembras, Valle del Lago Blanco, Chubut (Thursby) (BMNH); 1 macho, Lago Hermoso, P. Nac. Lanin, XI-1949, 1.: Schajovskoi; 1 hembra, Pucará, Neuquén, 1-V-1951, 1.: Schajovskoi (IML).

Citas bibliográficas. CHILE: Chiloé (Butler, 1882). ARGENTINA: San Martín de los Andes, Pucará (Orfila y Schajovskoy, 1959 (1960)).

\section{Franciscoia}

Franciscoia morenoi: ARGENTINA: 1 macho, HOLOTIPO, Pucará, Pcia. Neuquén, 10-I-1955, lg. S. Schajovskoi; 1 hembra, ALOTIPO, Pucará, Pcia. Neuquén, 10-I-1955; lg. S. Schajovskoi (MACN). CHILE: Concepción: 1 hembra, 23-X-1959, 1 hembra, 7-XI-1960, 1 hembra, 8-XI1960, Trampas coll.; 1 hembra, Osorno, 25-X-1988, coll. H. Ibarra-Vidal; Isla Teja, Valdivia: 4 machos y 5 hembras, 7-X1985, 2 machos, 2-3-X-1985 (MZUC).

Citas bibliográficas. CHILE: Curicó, Linares, Talca, Ñuble (Rindge, 1986). ARGENTINA: Pucará, San Martín de los Andes, Neuquén (Orfila y Schajovskoy, 1963; Rindge, 1986).

Franciscoia ediliae: HOLOTIPO, macho, Fundo Jauja, Prov. Malleco (IX Región de Chile), 23-VIII-1990, coll. C. Carrasco; ALOTIPO, hembra, mismos datos Holotipo (MZUC). PARATIPOS: 3 machos, 23-VIII-1990, 2 machos, 25-30-VII-1991, 2 machos, 20-30-VIII-1990 (MZUC); 3 machos, 23-VIII-1990 (MNHN), todos de Jauja, Prov. Malleco (IX Región de Chile), coll. C. Carrasco.

\section{Tanagridia}

Tanagridia rhaphis: CHILE: 1 macho, Quellón, Chiloé, 21-II-1956, J.S. Vargas coll. (MNHN).

Citas bibliográficas. CHILE: El Chinque (Llanquihue), La Cabaña (Cautín) (Rindge, 1986)

\section{Incalvertia}

Incalvertia valdiviana: CHILE: 1 macho, LECTOTIPO, Valdivia (MNHN); 1 macho, Chili, 91-131, 2 machos, Talcahuano, 84-72, 1 macho y 1 hembra, Talcahuano, 93162, 2 hembras, Mittel Chile, Contulmo, Schoënemann, 1 macho, Cauquenes, Schoënemann (BMNH). Material tipo de T. catophoenissoides Angulo (depositado en el MZUC): 1 macho, HOLOTIPO, Catillo, Linares, 27-III-1972, Trampas coll.; PARATIPOS: Concepción: 1 macho, 3-III-1959; 1 hembra 16-III-1959; 1 macho, 4-III-1960; 1 macho, 24-III1960; 1 macho, 6-III-1961; 1 hembra, 13-III-1961; 1 macho y 2 hembras, 20-III-1961; 1 macho, 25-III-1961; 1 macho, 10-III-1972; 1 macho, Catillo, Linares, 17-III-1972, Trampas coll.; 1 macho, Tirúa, 23-I-1952, G. Monsalve; 1 macho, Contulmo, Palo Botado, 2-II-1953, L.E. Peña; 1 macho, Bullileo, 23-III-1972, Trampas coll.

Citas bibliográficas. CHILE: Valdivia (Bartlett-Calvert, 1893a y 1893b). Linares, Concepción, Arauco (Angulo, 1977a). Chile central y sur (Rindge, 1986).

\section{Lacaria}

Lacaria araucanaria: ARGENTINA: 1 macho, HOLOTIPO, Lago Paimún, Prov. Neuquén, 21-I-1957, lg. S. Schajovskoi; 1 hembra, ALOTIPO, Pucará, P. Nac. Lanín, XI-1952, 1. Schajovskoy; PARATIPOS: Pucará, Prov. Neuquén: 1 hembra, IX-1952, S. Schajovskoy; 1 macho, X-1951, 1. Schajovskoy; 1 macho, 16-I-1957, 1. Schajovskoi (MACNBR); 1 macho, PARATYPE, Pucará, 3-I-1957, Prov. Neuquén, lg. S. Schajovskoi (BMNH); 1 macho, Nanthue, 650, Neuquén, 24-XII-190, coll. Schajovskoi (IML).

Citas bibliográficas. ARGENTINA: Pucará, Lago Paimún (Neuquén) (Orfila y Schajovskoy, 1959).

Lacaria orfilai: CHILE: 1 hembra, Contulmo, 12-IX1903 (BMNH); 1 hembra, Curacautín, 6-X-1948; 1 macho, Chiguayante, Manquimavida, 29-X-1961, Hulot coll.; 3 machos y 2 hembras, I. Teja, Valdivia, 7-X-1985; 1 hembra, Valdivia, I. Teja, 28-IX-1986, coll. D. Jackson (MZUC). ARGENTINA: 1 hembra, S.M. de los Andes, P. N. Lanín, X-1960, Schajovskoi; 4 machos y 1 hembra, Lago Queñi, Neuquén; Pucará, P.N. Lanín, Schajovskoi coll.: 1 hembra, 24-IX-1949; 1 macho y 1 hembra, 25-IX-1949; 1 macho, 26IX-1949; 1 hembra, I-1951 (BMNH); 2 machos, Nanthue, 650 m, Neuquén, 24-XII-1950, coll. Schajovskoi (IML).

Citas bibliográficas. ARGENTINA: Parque Nacional Lanín, Neuquén (Orfila y Schajovskoy, 1959).

Lacaria picuncharia: CHILE: 1 macho, Chile, Lanquihue Prov., F. \& M. Edwards (BMNH); 2 machos, Valdivia, I. Teja, 23-VII-1985, coll. D. Jackson (MNHN); Fundo Jauja, Prov. Malleco, Trampa UV coll.: 10 machos, 25-30-VII-1991, 2 machos, VIII-1990, 2 machos, 23-VIII-1990, 4 machos, 2030-VIII-1990, 5 machos, VII-1991, 3 machos y 2 hembras, VIII-1990; 1 macho, Valdivia, 25-VIII-1985, M. Béeche coll. (MZUC). ARGENTINA: 1 hembra, PARATYPE, Pucará, P.Nac. Lanín, I-1951, 1. Schajovskoi; 1 hembra, Lago Queñi, Neuquén (BMNH).

Citas bibliográficas. ARGENTINA: Pucará, Parque Nacional Lanín (Neuquén) (Orfila y Schajovskoy, 1959).

Lacaria schajovskoyi: CHILE: Contulmo: 1 macho, 8-IX1905, Schönemann; 1 macho, 19-IX-1903; 1 macho, 22-IX1903; 1 macho, 24-X-1903 (BMNH); 1 macho, Curacautín, 20-IX-1948 (MZUC); 1 hembra, Valdivia, I. Teja, 23-VII1985, coll. D. Jackson (MNHN). ARGENTINA: 1 macho, Lago hermoso, P. Nac. Lanín, XI-1949, 1. Schajovskoi; 1 macho, Pucará, P. Nac. Lanín, IX-X-1949, 1. Schajovskoi; (BMNH).

Citas bibliográficas. ARGENTINA: Pucará (Orfila y Schajovskoy, 1959). Lago Nonthue (Neuquén); San Martín de los Andes (Sperry, 1954).

\section{Maeandrogonaria}

Maeandrogonaria valentina: CHILE: 1 macho, HOLOTIPO (M. valentina), Chili, 93-139; 1 macho, Contulmo, 20-IX-1904; 1 hembra, Curacautín, 14-II-1950 (BMNH); 1 hembra, Curacautín 13-X-1950; Las Trancas, 
Cordillera de Chillán (Prov. Nuble) Trampa UV coll.: 2 hembras, 12-I-1996, 4 hembras, 17-I-1996; 1 hembra, Concepción, 16-I-1961, Trampa coll. (MZUC); 1 hembra, Curacautín, Cautín, II-1951; 1 macho, Isla Guafo, 1936 (MNHN). ARGENTINA: 1 macho, Chapelco, Terr. Neuquén 1000 m, 17-III-1950, (BMNH); 1 macho, PARATIPO ( $\boldsymbol{H}$. formosa), S. Martín de los Andes, 8-XI-1957, lg. M. Gentili (MACN).

Citas bibliográficas. CHILE: Talca, Valdivia, Río Negro (Rindge, 1986). ARGENTINA: Pucará, Chapalcó, San martín de los Andes (Orfila y Schajovskoy, 1964).

\section{Martindoelloia}

Martindoelloia juradoi: CHILE: 1 macho, Contulmo, 20IX-1905 (BMNH); 1 macho, Isla Teja, Valdivia, 7-X-1985, A. Aguilar coll. (MZUC). ARGENTINA: 1 macho, HOLOTIPO y 1 hembra, ALOTIPO, Pucará, XII-1959, R.N. y J.S. Orfila leg. (MACN); 1 macho, Chapelco 1000 m, Terr. Neuquén, 17-III-1950 (BMNH);

Citas bibliográficas. CHILE: Curicó, Bío-Bío, Llanquihue, Osorno, Chiloé (Rindge, 1986). ARGENTINA: Pucará, Neuquén (Orfila y Schajovsko, 1963).

\section{Nucara}

Nucara recurva: CHILE: 1 macho y 2 hembras, Chili, 93-139; 1 macho, Valparaíso, 84-72 (BMNH); 1 macho, Isla Teja, Valdivia, 2-3-X-1985; 1 hembra, Pucoihue, 12-X-1988, H. Ibarra-Vidal coll. (MZUC). ARGENTINA: 1 hembra, Pucará, P.N. Lanín, 23-IX-1941, Schajovskoi; 14 machos y 1 hembra, L. Correntoso, 18-25-XI-1926, Argentina, Terr. Río Negro, F. \& M. Edwards; 1 hembra, 23-X-1903; (BMNH).

Citas bibliográficas. CHILE: El Coigo (Curicó); Fundo Malcho (Parral, Linares) (Rindge, 1986).

\section{Odontothera}

Odontothera virescens: CHILE: 1 macho, HOLOTIPO, Chili, 82-107; 1 hembra, ALOTIPO, Chili, 82-107 (BMNH); 1 hembra, Quellón, Chiloé, 10-II-1956, J.S. Vargas coll. (MNHN); 1 macho, Curacautín, 2-II-1950; 1 macho, Río Blanco, Malleco, III-1951, col. L.E. Peña; 2 machos, Termas de Río Blanco, Cautín, III-1951 (MZUC).

Citas bibliográficas. CHILE: Corral (Butler, 1882). Dalcahue, Huequetrumao (Chiloé) (Rindge, 1986).

\section{Proteopharmacis}

Proteopharmacis valdiviata: CHILE: 1 macho, HOLOTIPO ( $S$. valdiviata), Chile; 1 macho, HOLOTIPO $(P$. trinotata), Chili; 1 macho, HOLOTIPO (P. trinotata var. subocellata), Chili; 1 macho, HOLOTIPO ( $P$. trinotata var. horrens), Chili; 1 macho, HOLOTIPO ( $P$. valdiviata var. clara), Chili; 1 macho, HOLOTIPO (P. clara), Chili; 1 macho, HOLOTIPO (P. mixta), Chili; 1 macho, HOLOTIPO y 1 hembra ALOTIPO (P. mixta var. seriata), Chili; 1 macho, HOLOTIPO (P. mixta var. melanosticta), Chili; 1 hembra,
HOLOTIPO ( $P$. mixta var. columba), Chili; 1 macho, HOLOTIPO ( $P$. ardescens), Chili; 1 macho, HOLOTIPO ( $P$. latifasciata), Chili; 1 hembra, HOLOTIPO ( $P$. latifasciata var. definita), Chili; 1 macho, HOLOTIPO (P. insignis), Chili (BMNH); 1 macho, Las Vizcachas, Limache, 27-XII-1936; 1 hembra, El Canelo, 16-II-1933; 1 macho, Peñalolén, 27-I1953; 1 macho, Rauco, 28-I-1948; 1 macho, El Canelo, 25XII-1936; 1 hembra, San Ignacio, Febrero (MNHN). Linares: 1 hembra, 17-I-1948, 1 hembra, I-1951, 25 machos y 12 hembras, XII-1949; 1 hembra, XII-1941; 1 macho, XII-1946 (MZUC). Concepción, Trampas UV coll.: 1 macho, 19-I-1947, 1 macho, 2-I-1959, 1 hembra, 5-II-1959, 1 macho, 5-I-1961, 2 hembras, 21-I-1961, 1 hembra, 6-II-1961, 1 hembra, 9-II1961, 2 hembras, 8-III-1961, 1 hembra, 14-I-1963 (MZUC). Algarrobo: 1 macho, 6-I-1950, 1 hembra, 11-I-1950; Termas de Río Blanco, Cautín: 1 macho, II-1951, 1 macho, III-1951; Nilahue: 2 machos y 4 hembras, 10-I-1949, 1 macho, 11-I1949, 1 macho y 1 hembra, 16-I-1949, 3 machos, 20-I-1949, 1 macho, 2-I-1950, 3 machos y 1 hembra, Nilahue, 1 hembra, 5-I-1950, 10-I-1950, 1 hembra, 11-I-1950, 1 hembra, 16-I1950, 1 hembra, 18-I-1950 (MZUC). 1 hembra, Maullín, II1943, S. Barros; 1 macho, Dichato, I-1951 (MZUC).

Citas bibliográficas. CHILE: Valparaíso (Butler, 1882). ARGENTINA: Pucará, San Martín de los Andes (Orfila y Schajovskoy, 1959 (1960)).

\section{Psilaspilates}

Psilaspilates catillata: CHILE: 1 macho, HOLOTIPO (P. catillata), Chile, 1 macho, HOLOTIPO (P. cavifasciata), Chili, 2 machos, Chili, Valdivia, Arturo V. Lossberg, 1901, 3 machos, Chili (BMNH); 1 macho, Maullín, 14-II-1942; 1 macho, Termas de Río Blanco, Cautín, II-1951; 1 macho, Chepu, Chiloé, I-1952, L.E. Peña; 1 macho, Concepción, 3-III-1959, Trampa coll. (MZUC). ARGENTINA: 1 macho, Valley Lago Blanco, Chubut, ,2 machos, Tierra del Fuego, Río Mc. Clelland, 30-XI-1904, 1 macho, S. América, Tierra del Fuego, Río Grande, Estancia Viamonte, 31-XII-1929 (BMNH); 1 macho, S.M. Andes, III-1950, 1. Schajovskoi (IML).

Citas bibliográficas. CHILE: Corral (Butler, 1882), Punta Arenas (Staudinger, 1898 (1899). ARGENTINA: Ushuaia (Staudinger, 1898 (1899)).

Psilaspilates cautinaria: CHILE: 1 macho, HOLOTIPO, Termas de Río Blanco, Cautín, III-1951; 1 macho, PARATIPO, Termas de Río Blanco, Cautín, II-1951 (MZUC).

Psilaspilates ceres: CHILE: 1 hembra, HOLOTIPO, Chili (BMNH); 1 macho, Concepción, 23-II-1961, Trampas coll.; 1 macho, Maullín, 20-I-1941 (MZUC). ARGENTINA: 1 hembra, Lago Hermoso, P.N. Lanin, XII-1949, 1. Schajovskoi; 1 hembra, Lago Hermoso, P.N. Lanin, XI-1949, 1. Schajovskoi (IML);

Citas bibliográficas. CHILE: Valparaíso (Butler, 1882).

Psilaspilates concepcionensis: CHILE: 1 macho, HOLOTIPO, 22-XI-1959, 1 hembra, ALOTIPO, 16-III- 
1962, Concepción, Trampa coll. PARATIPOS: Concepción, Trampa UV coll.: 1 macho, 6-III-1959, 1 macho y 1 hembra, 19-III-1959, 2 hembras, 16-II-1959, 2 hembras, 12-III-1972, 1 macho, 9-II-1961, 1 macho, 20-III-1958, 1 hembra, 26-III1958, 1 macho, 23-II-1959, 1 hembra, 3-III-1959, 1 hembra, 8-III-1959, 1 hembra, 23-III-1959, 1 hembra, 13-III-1959, 1 hembra, 10-III-1972; 1 hembra, Concepción, Villa Sta. Julia, 26-III-1971, Trampa coll.; 1 hembra, Chepu, Chiloé, I-1952, L.E. Peña; 1 hembra, Catillo, 22-III-1972, trampas coll.; 1 hembra, Maullín, 21-I-1941; 1 macho, Linares, 16III-1949; 1 hembra, Termas de Río Blanco, Cautin, II-1951; 1 hembra, Curacautín. 14-II-1950; 1 macho, Catillo, 14-II1972, trampas coll.; 1 macho, Bullileo, 21-III-1972, Trampas coll.; 1 macho, Catillo, 22-III-1972, Trampas coll. (MZUC).

Psilaspilates obscura: CHILE: 1 macho, HOLOTIPO, Concepción, 8-III-1959, Trampas coll.; 1 hembra, ALOTIPO, Concepción, 17-III-1960, Trampas coll.; PARATIPOS: Concepción, Trampa UV coll.: 1 macho, Maullín, 24-I-1941; 1 macho, 15-II-1959, 1 macho, 1-III-1959, 1 macho, 7-III1959, 1 macho, 20-III-1961, 1 macho, 28-II-1959 (MZUC).

Psilaspilates signistriata: CHILE: 1 macho, HOLOTIPO, Chili, 82-107, 1 hembra, ALOTIPO, Chili, 82-107, 1 macho, Valdivia, 1901, Arturo V. Lossberg, 1 macho, Chili, 1 macho, Panguipulli, 18-I-1928, A. Fay. (BMNH). Concepción, Trampa UV coll.: 1 hembra, 4-III-1960, 1 macho, 2-III-1959, 1 hembra, 25-II-1959, 1 macho, 14-II-1959, 1 macho, 16III-1959, 1 hembra, 19-II-1959, 1 macho y 1 hembra, 16-II1959, 1 macho, 3-III-1959, 1 macho, 19-II-1960, 1 macho, 8-III-1959, 1 macho, 2-II-1960, 1 macho, 22-III-1961, 1 hembra, 7-III-1959, 1 hembra, 16-III-1959, 1 macho, 13-III1960, 1 hembra, 10-III-1960, 1 macho, 19-II-1961, 1 macho, 2-III-1961, 1 hembra, 21-III-1961, 1 hembra, 24-III-1962, 1 hembra, 27-II-1960, 1 hembra, 1-III-1961, 1 hembra, 2-III1961, 1 macho, 8-III-1961, 1 hembra, 3-II-1961, 1 hembra, 1-III-1961, 1 hembra, 7-III-1961, 1 macho, 13-III-1961 (MZUC). Maullín: 1 macho, 20-I-1941, 1 macho, 23-I-1941, 2 macho y 1 hembra, 21-I- 1941, 1 hembra, 10-II-1943, 1 macho, 20-Y-1942 (MZUC). Curacautín: 1 hembra, 14-II-
1960, 1 macho, 14-II-1950, 1 hembra, 16-XII-1950 (MZUC). Termas de Río Blanco, Cautín: 2 machos, III-1951, 2 machos, II-1951 (MZUC). 1 macho, Guayacán, III-1951; 1 macho, Lonquimay, Cautín, II-1951; 1 macho, Contulmo, 2-II-1953, L.E. Peña coll.; Las Selvas, Nahuelbuta: 1 macho, 26-II1952, 2 machos, 26-I-1952, G. Monsalves coll.; 1 macho. Loncotrimay, Nahuelbuta, 27-I-1952, G. Monsalves coll. (MZUC); 1 macho, Viña del Mar, 28-III-1953 (MNHN). ARGENTINA: 1 macho, Santa Cruz, Río Turbio, 29-XII1954; 1 hembra, Pucará, Neuquén, 1-V-1951, 1. Schajovskoi (IML).

Citas bibliográficas. CHILE: Corral (Butler, 1882), Punta Arenas (Staudinger, 1898 (1899)). ARGENTINA: Ushuaia, Río Grande (Staudinger, 1898 (1899)).

Psilaspilates stygiana: CHILE: 1 macho, HOLOTIPO $(H$. stygiana), Chili, 82-107, 1 macho, HOLOTIPO (H. stygiana var. aurea), Chili, 82-107, 1 macho, Chili, 82-107, 1 macho y 1 hembra, Chili, Edmonds, 1 hembra, Princi., II-1888, V. Izquierdo (BMNH); 1 macho y 1 hembra, Principal, II-1892; 1 macho, Bellavista, 14-III-1953; 1 macho, Los Queñes, II-1949; 1 macho, sin datos; 1 hembra, Principal, II-1888 (MNHN).

Citas bibliográficas. CHILE: Valparaíso (Butler, 1882).

Psilaspilates venata: CHILE: 1 macho, HOLOTIPO, Chili, 82-107; 3 machos, Mittlel Chile, Contulmo, Schönemann S.; 1 hembra, Valparaíso, Chile; 5 machos, Chili; 1 macho, Chili, Mulchen, I-1902, H.J. Elwes (BMNH); 1 macho, Contulmo, Palo Botado, 2-II-1953, L.E. Peña; 1 macho, Concepción, 23II-1961, Trampas coll.; 2 hembras, Puyehue, 2-II-1980, J.E. Barriga (MZUC).

\section{Rhinoligia}

Rhinoligia biocellata: CHILE: 1 macho, Araucania, II1888; 1 hembra, Pemehue, IX-XII, Dr. Izquierdo; 1 hembra, Pemehue, 790m, 12-I-1946; 1 hembra, Concepción, 3-I1962; (MNHN); 1 hembra, Concepción, 5-I-1961, Trampa coll. (MZUC). 